\title{
Colon cancer-associated transcript-1 enhances glucose metabolism and colon cancer cell activity in a high-glucose environment in vitro and in vivo
}

\author{
Ge Cui ${ }^{1 \#}$, Yuxuan Huang ${ }^{2 \#}$, Wenming Feng ${ }^{3}$, Yunliang Yao ${ }^{4}$, Hongchang Zhou ${ }^{5}$ Xining $\mathrm{Li}^{6}$, $\mathrm{Hui} \mathrm{Gong}^{7}$, \\ Jun Liu ${ }^{8}$, Yifan Luo $^{8}$, Yandi Sun ${ }^{9,10}$, Mengya Zhang, ${ }^{9,10}$, Yan Luo ${ }^{9,10}$, Ting Zhang ${ }^{6}$ \\ ${ }^{1}$ Department of Pathology, The First Affiliated Hospital of Huzhou University, Huzhou, China; ${ }^{2}$ School of Medicine, Huaqiao University, \\ Quanzhou, Fujian, China; ${ }^{3}$ Department of Surgery, The First Affiliated Hospital of Huzhou University, Huzhou, China; Key Laboratory of Vector \\ Biology and Pathogen Control of Zhejiang Province, Huzhou University, Huzhou Central Hospital, Huzhou, China; ${ }^{5}$ Department of Pathogenic \\ Biology, School of Medicine and Nursing Sciences, Huzhou University, Huzhou Central Hospital, Huzhou, China; ${ }^{6}$ Department of Pathology, \\ School of Medicine and Nursing Sciences, Huzhou University, Huzhou Central Hospital, Huzhou, China; ${ }^{7}$ Central Laboratory, The First Affiliated \\ Hospital of Huzhou University, Huzhou, China; ${ }^{8}$ School of Medicine and Nursing Sciences, Huzhou University, Huzhou Central Hospital, Huzhou, \\ China; ${ }^{9}$ Department of Biochemistry and Cancer Institute of the Second Affiliated Hospital, Zhejiang University School of Medicine, Hangzhou, \\ China; ${ }^{10}$ Key Laboratory of Cancer Prevention and Intervention of China National Ministry of Education, Hangzhou, China \\ Contributions: (I) Conception and design: G Cui, W Feng, T Zhang; (II) Administrative support: W Feng; (III) Provision of study materials or \\ patients: W Feng; (IV) Collection and assembly of data: Y Huang, Y Sun, M Zhang, J Liu, Y Luo, H Gong; (V) Data analysis and interpretation: G \\ Cui, Y Huang, Y Yao, H Zhou, X Li; (VI) Manuscript writing: All authors; (VII) Final approval of manuscript: All authors. \\ \#These authors contributed equally to this work. \\ Correspondence to: Ting Zhang. Associate Professor, Department of Pathology, School of Medicine and Nursing Sciences, Huzhou University, \\ Huzhou Central Hospital, No. 759 Er Huan Dong Road, Huzhou University, Huzhou 313000, China. Email: grapechang@qq.com.
}

\begin{abstract}
Background: Our study aims to investigate the effect of colon cancer-associated transcript-1 (CCAT-1) on colon cancer cells' activity and metabolism under different glucose environments in vitro and in vivo.

Methods: The levels of proliferation, migration, glucose, lactic acid, glucose metabolism-related enzymes, apoptosis genes, epithelial-mesenchymal transition (EMT) marker proteins, and PI3K/Akt/C-MYC pathway in CCAT-1-silenced SW620 cells cultured with different glucose levels were tested. Twenty BALB/C nude mice with hyperglycemia or normal blood sugar were transplanted with CCAT-1-silenced SW620 cells, blood glucose levels, lactic acid, insulin, and volume of transplanted tumor cells, the expression of EMT marker proteins, and PI3K/Akt/C-MYC pathway was detected.

Results: The levels of proliferation, migration, glucose, lactic acid, LDH-A, PKM2, and HK2 decreased, apoptosis increased in SW620 cells cultured with low glucose or silenced CCAT-1 $(\mathrm{P}<0.05)$; levels of E-cadherin and ZO-1 significantly increased, and levels of N-cadherin, vimentin, and p-Akt decreased in CCAT-1-silenced SW620 cells cultured with high glucose $(\mathrm{P}<0.05)$. Hyperglycemic nude mice transplanted with CCAT-1-silenced colon cancer cells showed decreased tumor volume, blood glucose, lactic acid, insulin, $\mathrm{P}-\mathrm{AKT}$, and $\mathrm{P}-\mathrm{C}-\mathrm{MYC}$ than EV group $(\mathrm{P}<0.05)$.

Conclusions: CCAT-1 can enhance glucose metabolism and proliferation and migration of colon cancer cells by upregulating the expression of glycolysis enzymes, inhibiting apoptosis, activating the Akt/C-MYC pathway, and promoting EMT expression.
\end{abstract}

Keywords: Colon cancer-related transcript-1 (CCAT-1); colon cancer; hyperglycemia; glucose metabolism; PI3K signaling pathway; C-MYC

^ ORCID: Ge Cui, 0000-0003-1777-4769; Ting Zhang, 0000-0003-1777-4769. 
Submitted Sep 28, 2020. Accepted for publication Dec 04, 2020.

doi: 10.21037/jgo-20-474

View this article at: http://dx.doi.org/10.21037/jgo-20-474

\section{Introduction}

Epidemiological studies have found that hyperglycemia, mainly types two diabetes mellitus, is an independent risk factor for colon cancer, increasing colon cancer incidence and affecting the recurrence, metastasis, and prognosis in colon cancer patients (1-14).

Our previous study found that $29.67 \%$ of colon cancer patients were hyperglycemic. The degree of pathological changes and prognosis of colon cancer in patients with hyperglycemia were worse (9), suggesting that the blood glucose level can significantly affect malignancy and disease progression. However, the relationship between hyperglycemia and colon cancer is still unclear.

We used an Illumina HiSeq sequencer to sequence 120 colon cancer tissue samples' transcriptome and screened out the molecular spectrum of relatively high expression in hyperglycemia colorectal cancer tissues. We found that the RNA expression of colon cancer-associated transcript-1 (CCAT-1) increased significantly in the tumor tissue of colon cancer patients with hyperglycemia through verification via qPCR. CCAT-1 is a long-chain non-coding RNA with high specificity and sensitivity in colon cancer (15) and promotes autophagy in hepatocellular carcinoma (16), we speculated that $C C A T-1$ is involved in the incidence and development of colon cancer in a high glucose environment, but we need to confirm its role further and explore its mechanism.

This study verified the expression level of CCAT-1 in colon cancer tissues with different blood glucose levels and different glucose culture environments. We further combined these findings with research methods of molecular cell biology and experimental zoology (establishing hyperglycemic nude mouse model for colon cancer transplantation by BALB/C nude mice) to find the effects of $C C A T-1$ on proliferation, migration, and metabolism of colon cancer cells in vitro and vivo. Finally, we explored the molecular mechanism of CCAT-1. We clarified the role of CCAT-1 in colon cancer and hyperglycemia by providing a theoretical and experimental basis for developing a CCAT-1-targeted, individualized treatment strategy for hyperglycemic patients with colon cancer.

We present the following article in accordance with the
ARRIVE reporting checklist (available at http://dx.doi. org/10.21037/jgo-20-474).

\section{Methods}

\section{Clinical samples}

Two hundred paired tumor tissues and matched noncancerous tissues were collected at our hospital. All procedures performed in this study involving human participants were in accordance with the Declaration of Helsinki (as revised in 2013). The study was approved by Ethics Committee board of The First Affiliated Hospital of Huzhou University (No.: 20170118003) and informed consent was taken from all the patients.

Patients with colon cancer who were admitted for the first time with a clinical diagnosis of colon cancer, those who had not undergone radiotherapy or chemotherapy and had not received traditional Chinese medicine or any other tumor treatment within the past month, and those who were diagnosed with colon cancer by a senior diagnostic physician of the pathology department were included in the study. Patients with familial adenomatous polyposis, various acute and chronic infectious inflammations, severe cardiovascular and cerebrovascular diseases (such as acute coronary syndrome, cardiac insufficiency, and cerebrovascular accident), liver and kidney function damage, and other stress conditions were excluded. Two hundred patients with colon cancer who met the abovementioned criteria were included in our standardized clinical, biological sample bank for surgical resection of tumor tissue and distal normal intestinal mucosal tissue.

\section{Detection of blood glucose levels and tissue grouping in patients with colon cancer}

The glucose oxidase method was used to detect the venous fasting plasma glucose (FPG) value of fasting colon cancer patients $(\mathrm{mmol} / \mathrm{L})$ in the morning, and the procedure was performed according to the instructions mentioned in the Glucose Test kit (YZB/Hu 2624-40-2014, Shanghai Rongsheng Biology, CHN). The blood glucose standard was determined according to WHO diagnostic standard (17): the reference value for fasting blood glucose in normal 
individuals was 3.9-6.1 $\mathrm{mmol} / \mathrm{L}$, that in hyperglycemic individuals was over $6.1 \mathrm{mmol} / \mathrm{L}$, that in individuals with diabetes mellitus (DM) was over $7.0 \mathrm{mmol} / \mathrm{L}$ or had diabetes symptoms. Furthermore, the venous blood glucose concentration in individuals with DM was over $11.1 \mathrm{mmol} /$ L. According to the blood glucose levels and the benign and malignant tissue, the patient samples were divided into four groups: colorectal tumor tissue (HG-T) and normal tissue (HG-N) of patients with hyperglycemia and colorectal tumor tissue (NG-T) and normal tissue (NG-N) of patients with normal blood glucose levels.

\section{Detection of CCAT-1 RNA expression in colon cancer patients with different blood glucose statuses}

RNA was extracted from tissue samples, and agarose (2\%) gel electrophoresis was performed. According to the specifications of a qPCR RT kit (DBI Bestar ${ }^{\circledR} 2220$, GER), a reverse transcription reaction system was prepared to synthesize the first strand of cDNA, which was collected and stored for future use. Shanghai biotechnology Service Co., Ltd synthesized design, and synthesis primers (primer sequence, Table 1). The real-time fluorescent quantitative PCR experiment was performed using the Agilent StrataGene fluorescent quantitative PCR instrument Mx3000p. PCR amplification was performed using the SYBRGREEN qPCR Master Mix kit (DBI Bestar ${ }^{\circledR} 2043$, GER): reaction conditions: $95{ }^{\circ} \mathrm{C} 2$ minutes; $94{ }^{\circ} \mathrm{C} 20$ seconds; $58^{\circ} \mathrm{C} 20$ seconds, 40 cycles; melting curve analysis: temperature $65^{\circ} \mathrm{C}$ to $95^{\circ} \mathrm{C}$. The procedure was repeated three times for each sample. The data were processed by the $2^{-\Delta \Delta \mathrm{Ct}}$ method. $\Delta \mathrm{Ct}=$ target gene $\mathrm{Ct}-$ internal reference $\mathrm{Ct}$ (mean \pm standard deviation); $\triangle \triangle \mathrm{Ct}=\Delta \mathrm{Ct}$ of the target gene in the sample to be tested $-\triangle \mathrm{Ct}$ of the target gene in the reference sample (mean \pm standard deviation; if there is no reference sample, select the sample with the most extensive $\mathrm{Ct}$ as the reference for calculation). The relative sample initial template amount $=2^{-\Delta \Delta \mathrm{Ct}}($ mean \pm standard deviation). The results were analyzed using the ABI Prism 7300 SDS Software (Applied Biosystems Foster City, CA, USA), and the relative RNA expression was calculated. The experiment was repeated three times.

\section{Cell culture}

The colon cancer cell line LoVo (ATCC CCL-229, USA), SW620 (ATCC CCL-228, USA), and normal colon cells FHC (ATCC CRL-1831, USA) were retrieved from the Cell 
Bank of the Chinese Academy of Sciences (Shanghai, CHN). The cells were cultured at $37{ }^{\circ} \mathrm{C}, 5 \% \mathrm{CO}_{2}$, and saturated humidity with a high concentration of glucose DMEM (glucose content $4.5 \mathrm{~g} / \mathrm{L}$, concentration $25 \mathrm{mmol} / \mathrm{L}$ ) and low glucose DMEM (glucose content $1.0 \mathrm{~g} / \mathrm{L}$, concentration $5.6 \mathrm{mmol} / \mathrm{L})$. At the logarithmic growth stage, the cells were digested with $0.25 \%$ trypsin solution.

\section{Detection of CCAT-1 RNA expression in colon cancer cells by $q$ PCR}

RNA was extracted from two colon cancer cell lines (LoVo and SW620) and normal colon cells (FHC), and the expression level of $C C A T-1$ was detected by qPCR. The procedure followed for $\mathrm{qPCR}$ is the same that was mention in section Results.

\section{Construction of CCAT-1 lentivirus vectors to transfect colon cancer cells and cell grouping}

The DNA oligonucleotide was designed with the software designer 3.0 (GENEPHARMA, CHN), and GENEPHARMA Pharmaceutical Technology Co. provided the synthetic primers, Ltd. Reagents included DNA endonuclease (BpiI, \#ER1011, PstI, \#ER0611, BamHI, \#ER0051, MBI Fermentas, Lithuania), DNA ligase (\#EL0011, MBI Fermentas, Lithuania), DNA markers (\#SM0161, MBI Fermentas, Lithuania). For the construction of $C C A T-1$ lentivirus vectors, $C C A T-1$ shRNA primers were synthesized and connected to the U6 promoter of lentivirus vectors for constructing the target shRNA plasmid. Following this, CCAT-1 shRNA plasmid and the auxiliary plasmid were co-transfected into 293T cells for verification, and the virus solution was collected, concentrated, and determined. The colon cancer cell line SW620 (ATCC CCL-228, USA) was infected with CCAT-1 shRNA plasmid virus solution.

RNAi interference efficiency was identified via qPCR. Based on CCAT-1 silencing, empty vector transfection, and different glucose medium cultivating environments, the cells were divided into four groups: $C C A T-1$-silenced cells cultured with high glucose concentration (HG-CCAT-1 ${ }^{-}$), empty vector-transfected cells cultured with high glucose concentration (HG-EV), CCAT-1-silenced cells cultured with low glucose concentration (LG-CCAT-1-), and empty vector-transfected cells cultured with low glucose concentration (LG-EV).

\section{Proliferative activity of colon cancer cells detected by EdU flow cytometry}

Here, $1 \times 10^{6}$ cells per well were inoculated into a 6 -well culture plate, and $1 \mathrm{~mL}$ of $50 \mu \mathrm{m} \mathrm{EdU} \mathrm{(5-ethynyl-2'-}$ deoxyuridine, RiboBio, R11056.5) culture medium was added to each well, which was followed by incubation for 2 hours. The cells were collected into flow tubes and centrifuged at 1,500 rpm. Following this, cells in each tube were resuspended with PBS, fixed with $4 \%$ paraformaldehyde for 30 minutes, neutralized with $2 \mathrm{mg} / \mathrm{mL}$ glycine for 5 minutes, and incubated with $0.5 \%$ Triton X-100 penetrant at room temperature for 10 minutes. Subsequently, $500 \mu \mathrm{L}$ of $1 \times$ Apollo staining reaction solution (Apollo ${ }^{\circledR} 488 \mathrm{C} 00051$ ) was added to each tube. The cells were resuspended and incubated at room temperature without light for 10 minutes, centrifuged at 1,500 rpm for 5 minutes, and the staining reaction solution was discarded. The cells were washed with PBS three times. The fluorescence of the Apollo 488 channel was detected by flow cytometry (BD Biosciences, US). The percentage of S-phase cells was calculated, and cell proliferation was analyzed.

\section{Migration activity of colon cancer cells as detected by the Transwell migration assay}

Colon cancer cells in the logarithmic growth phase were collected and inoculated into the upper chamber of a 24-well inserted culture plate ( $400 \mu \mathrm{L} /$ well; including $2 \times 10^{5}$ cells). The cells holding $20 \%$ FBS were added to the lower chamber, and the polycarbonate microporous membrane (pore size, $8 \mu \mathrm{m}$ ) was placed between the upper and lower chambers. After 18 hours of culture, the upper chamber fluid was discarded to remove the non-adherent cells. This was followed by fixation with $95 \%$ ethanol and Giemsa staining. The cells were counted under a light microscope $(200 \times)$. Calculated mobility $(\%)=$ (number of lower layer cells/number of added cells) $\times 100$. Calculated migration promotion rate $(\%)=$ (number of migrated cells in the experimental group - number of migrated cells in the control group)/number of migrated cells in the control group $\times 100$.

\section{Glucose and lactic acid levels in colon cancer cells as detected by ELISA}

ELISA detected glucose and lactic acid levels in the four 
groups of cells. The culture medium was drawn in a culture plate, cells were digested with trypsin, and the proper amount of culture medium was added to blow the cells off the culture plate. The precipitate was discarded. The cell suspension was collected and centrifuged at 1,000 $\times g$ for 10 minutes, and the culture medium was discarded. The cell suspension was rinsed three times with precooled PBS; an adequate amount of precooled PBS was added to resuspend the cells, and the cells were lysed by ultrasound exposure. The centrifugation was performed at $4{ }^{\circ} \mathrm{C}$ for 10 minutes at $10,000 \times \mathrm{g}$, cell fragments were removed, and the supernatant was absorbed. The procedures were performed according to the steps included in the Glucose ELISA Kit (YZB/Hu 2624-40-2014, Shanghai Rongsheng Biology, CHN) and Lactic acid ELISA Kit (A019-2, Nanjing Jiancheng, CHN). A working solution was prepared by mixing the calibrator, distilled water, and cell samples, and suspended in a water bath at $37{ }^{\circ} \mathrm{C}$ for 15 minutes. The absorbance values at $505 \mathrm{~nm}$ (glucose) and $530 \mathrm{~nm}$ (lactic acid) were separately determined using an automatic biochemical analyzer (TBA-40, TOSHIBA, JPN). Considering the standard substance's concentration as the abscissa and the OD value as the ordinate, a standard curve was drawn. The sample calculation formula is: sample concentration $(\mathrm{mmol} / \mathrm{L})=($ measured OD value - blank OD value $) /($ standard $\mathrm{OD}$ value - blank $\mathrm{OD}$ value $) \times$ standard concentration $(\mathrm{mmol} / \mathrm{L}) \times$ dilution times before test.

\section{Protein expression detected by Western blotting}

The expression levels of LDH-A, pkm2, hK2, Bcl-2, Bax, E-cadherin, vimentin, phosphatidylinositol-3-kinases $(\mathrm{PI} 3 \mathrm{~K}) /$ protein serine-threonine kinase $(\mathrm{Akt}) /$ cellularmyelocytomatosis viral oncogene (C-MYC), and their phosphorylated proteins were detected by Western blotting.

The total protein was extracted using the Ripa lysate and measured via the Bradford method. Following this, $50 \mu \mathrm{g}$ of total protein was used for gel electrophoresis $(300 \mathrm{~mA})$, and the proteins were transferred onto a PVDF membrane (Millipore, IPVH00010, USA). The transfer efficiency was determined via Coomassie brilliant blue staining. The PVDF film was rinsed for 5 minutes with $25 \mathrm{~mL}$ Trisbuffered saline (TBS), and $5 \%$ degreasing milk powder with TBS was added as a sealing solution. The solution was then placed on an orbital shaker (MaxQ8000, Thermo Scientific, USA) to shake gently overnight at $4{ }^{\circ} \mathrm{C}$; further, $25 \mathrm{~mL}$ TBS was used to scour the membrane three times. The PVDF membrane was dipped into $3 \mathrm{~mL}$ of diluted corresponding antibodies: LDH (dilution ratio 1:5,000, $300 \mathrm{~mA}$, 35 minutes), PKM2 (dilution ratio 1:1,000, $300 \mathrm{~mA}$, 55 minutes), HK2 (dilution ratio 1:2,000, $300 \mathrm{~mA}, 50$ minutes), Bcl-2 (dilution ratio 1:1,000, $300 \mathrm{~mA}, 25$ minutes), Bax (dilution ratio 1:2,000, $300 \mathrm{~mA}, 20$ minutes), E-cadherin (dilution ratio 1:1,000, $300 \mathrm{~mA}, 90$ minutes), ZO-1 (dilution ratio $1: 2,000,300 \mathrm{~mA}, 120$ minutes), $\mathrm{N}$-cadherin (dilution ratio $1: 1,000,300 \mathrm{~mA}, 100$ minutes), Vimentin (dilution ratio $1: 1,000,300 \mathrm{~mA}, 50$ minutes), $\mathrm{PI} 3 \mathrm{~K}$ (dilution ratio $1: 2,000,300 \mathrm{~mA}, 80$ minutes), P-PI3K (dilution ratio 1:1,000, $300 \mathrm{~mA}, 80$ minutes), Akt (dilution ratio 1:500, $300 \mathrm{~mA}, 55$ minutes), p-Akt (dilution ratio 1:3,000, $300 \mathrm{~mA}$, 55 minutes), C-MYC (dilution ratio: 1:5,000, $300 \mathrm{~mA}$, 50 minutes), p-C-MYC (dilution ratio: 1:1,000, $300 \mathrm{~mA}$, 50 minutes), and GAPDH (Abcam, ab8245, dilution ratio: $1: 10,000)$. Following this, the membrane was placed in a $5 \%$ skimmed milk powder TBS solution and put in the shaker's upper chamber. The PVDF membrane was washed with $25 \mathrm{~mL}$ TBST three times for 5 minutes each time. The PVDF membrane was then placed into a small tank containing $3 \mathrm{~mL}$ of diluted secondary antibody solution labeled with horseradish peroxidase, and then shaken on a shaking bed for 40 minutes at room temperature (HRP Goat anti-rabbit IgG; booster, ba1054, dilution ratio: 1:20,000), and incubated at room temperature for 40 minutes. The PVDF membrane was washed with $25 \mathrm{~mL}$ TBST three times for 7 minutes each time.

Furthermore, the abovementioned antibody was washed with $25 \mathrm{~mL}$ TBST; after incubation, the PVDF membrane protein was placed on a fresh-keeping film, and the mixture was mixed with an appropriate amount of liquid. The tablets were placed in the medical X-clip and added with an ECL chemiluminescence display agent. An image analysis software scanned the film and analyzed the strip net OD with a gel image processing system (Image-Pro Plus 6.0, Media Cybernetics, USA). The relative intensity of target protein expression was calculated: relative intensity of target protein expression $=$ gray value of the target strip/gray value of the GAPDH strip.

\section{Construction of hyperglycemic nude mouse model}

In this analysis, $20 \mathrm{BALB} / \mathrm{C}$ nude mice (Shanghai SLAC Laboratory Animal Co.,Ltd), aged 5-6 weeks, weighing $18.0 \pm 0.5 \mathrm{~g}$, were reared at $22{ }^{\circ} \mathrm{C}$ room temperature and SPF for 12 hours/12 hours and were randomly divided into hyperglycemia group (HG) and control group (10 rats in each group). In the hyperglycemia group, $40 \mathrm{mg} / \mathrm{kg}$ 
streptozotocin (STZ, Sigma Chemical Co., St. Louis, MO) was injected into the peritoneum for five consecutive days, blood was drawn from the tail, and serum glucose content was measured via a biochemical method. Those with random blood glucose values $\geq 16.7 \mathrm{mmol} / \mathrm{L}(300 \mathrm{mg} / \mathrm{dL})$ and fasting blood glucose value $>10 \mathrm{mmol} / \mathrm{L}$ were used in the hyperglycemic nude mouse model (18) [modeling operation and evaluation method reported before (18)]. The control group was injected intraperitoneally with the same amount of normal saline. Animal experiments have approved by the review of Ethics Committee board of The First Affiliated Hospital of Huzhou University (No.: 20170118003), and were performed in compliance with Chinese national or institutional guidelines for the care and use of animals.

\section{Construction of a byperglycemic nude mouse model for colon cancer transplantation, mouse grouping, and detection}

The nude mice were divided into four groups: nude mice with normal blood glucose transplanted with empty vector-transfected colon cancer cells (NG-EV), nude mice with normal blood glucose transplanted with CCAT-1silenced colon cancer cells (NG-CCAT-1 ${ }^{-}$), nude mice with hyperglycemia transplanted with empty vectortransfected colon cancer cells (HG-EV), and nude mice with hyperglycemia transplanted with $C C A T$-1-silenced colon cancer cells (HG-CCAT-1 ${ }^{-}$).

The abovementioned CCAT-1 shRNA-transfected colon cancer cells were subcutaneously transplanted into an axillary site in nude mice in NG-CCAT-1 $1^{-}$group and HG-CCAT- $1^{-}$group at the dose of $0.2 \mathrm{~mL}$ (cell suspension concentration: $1 \times 10^{7}$ ) separately, with five nude mice being transplanted in each group. The same dose of empty vector shRNA-transfected colon cancer cells was transplanted into nude mice in the NG-EV and HG-EV groups separately, with five nude mice transplanted per group.

Four weeks after cell transplantation, the nude mice were anesthetized with $10 \%$ chloral hydrate at the concentration of $0.03 \mathrm{~mL} / \mathrm{kg}$. The nude mice were fixed on their backs, and blood was drawn from the hearts of mice. Blood samples were collected in centrifugation tubes without pyrogen and endotoxin. The centrifugation tube was placed at room temperature for 2 hours to retrieve the serum precipitate, followed by centrifugation at $1,000 \times \mathrm{g}$ at $4{ }^{\circ} \mathrm{C}$ for 20 minutes, and the supernatant was carefully collected. ELISA measured serum glucose, lactic acid, and insulin, as per the instructions mentioned in the Glucose ELISA Kit (YZB 2624-40-2014; Shanghai Rongsheng, CHN), Lactic acid ELISA Kit (A019-
2, Nanjing Jiancheng, CHN), and Insulin ELISA Kit (CSBE05071m, CUSABIO, USA), respectively. The absorbance value was found at $505 \mathrm{~nm}$ for glucose, $530 \mathrm{~nm}$ for lactic acid, and $450 \mathrm{~nm}$ for insulin using an automatic biochemical analyzer (TBA-40, TOSHIBA, JPN). The standard substance concentration, abscissa, and the OD value as the ordinate to draw a standard curve, and the corresponding concentration values were determined from the standard curve depending on the sample's OD value. This concentration value retrieved from the curve was multiplied by a dilution multiple to retrieve the sample's actual concentration. Vernier caliper measured the volume of the tumor. Western blotting was performed to detect the expression of epithelialmesenchymal transition (EMT) marker proteins and the activation of the PI3K/Akt/C-MYC pathway.

\section{Statistical analyses}

SPSS 25.0 (IBM, USA) was used for data analysis; count data are expressed as mean \pm standard deviation. The mean value between groups was compared by paired sample $t$-test, with $\mathrm{P}<0.05$ showing statistical significance. $\log$ transformations for exponents and ratios and logit transformations for proportions/percentages were conducted beforehand to approximate a normal distribution.

\section{Results}

\section{Blood glucose statistics in colon cancer patients}

According to the statistics of fasting blood glucose status, 131 of 200 patients with colon cancer had normal blood glucose levels (fasting blood glucose level, 3.9-6.1 mmol/L), accounting for $65.50 \%$ of the total number of patients with colon cancer. Furthermore, 61 of the 200 patients had hyperglycemia (fasting blood glucose level $>6.1 \mathrm{mmol} / \mathrm{L}$ ), accounting for $30.50 \%$ of the total number of patients with colon cancer; of these 61 patients, 29 had diabetes (fasting blood glucose level $\geq 7.0 \mathrm{mmol} / \mathrm{L}+$ clinical confirmation). Finally, 8 of the 200 patients had hypoglycemia (fasting blood glucose $<3.9 \mathrm{mmol} / \mathrm{L}$ ), accounting for $4.00 \%$ of the total number of colon cancer patients.

CCAT-1 RNA expression in tumor and normal tissues of colon cancer patients with different blood glucose levels

The relative expression levels of CCAT-1 RNA in HG-T, HG-N, NG-T, and NG-N groups were determined, and 


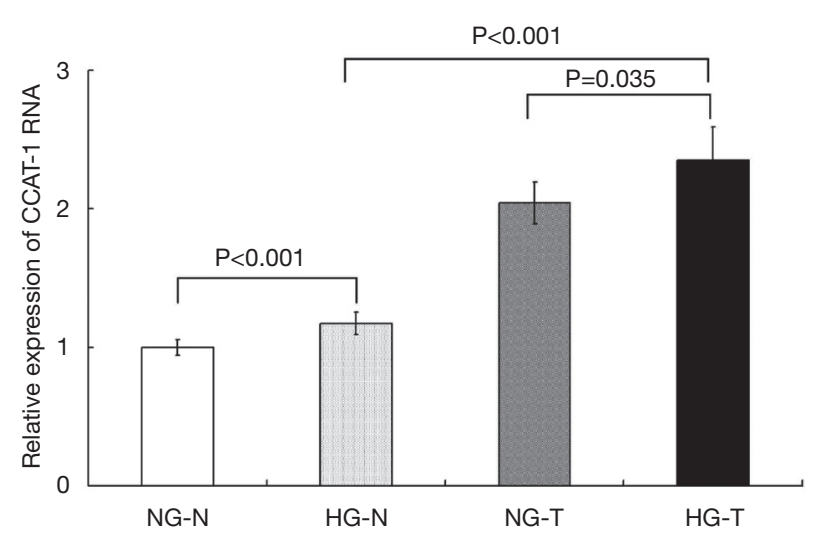

Figure 1 Expression of colon cancer-associated transcript-1 (CCAT-1) RNA in tumor and normal tissues of colon cancer patients with different blood glucose statuses. CCAT-1 RNA expression in tumor tissues of colon cancer patients with normal blood glucose levels was significantly higher than that in the distal normal intestinal mucosa $(\mathrm{t}=4.880, \mathrm{P}<0.001)$. CCAT-1 RNA expression in tumor tissues of colon cancer patients with hyperglycemia was significantly higher than that in the distal normal intestinal mucosa $(\mathrm{t}=6.232, \mathrm{P}<0.001)$. Furthermore, CCAT1 RNA expression was significantly higher in colon cancer patients tissues with hyperglycemia than in tumor tissues of colon cancer patients with normal blood glucose levels $(\mathrm{t}=2.400, \mathrm{P}=0.035)$. NG$\mathrm{N}$, normal mucosa tissue from colon cancer patients with normal blood glucose; HG-N, normal mucosa tissue from colon cancer patients with high blood glucose; NG-T, tumor tissue from colon cancer patients with normal blood glucose; HG-T, tumor tissue from colon cancer patients with high blood glucose.

the differences in CCAT-1 RNA expression were compared by $t$-test. The results are shown in Figure 1 .

The results showed that CCAT-1 RNA expression in tumor tissues of colon cancer patients with normal blood glucose levels was significantly higher than that in the distal normal intestinal mucosa $(\mathrm{t}=4.880, \mathrm{P}<0.001)$. CCAT -1 RNA expression in tumor tissue of colon cancer patients with hyperglycemia was significantly higher than that in the distal normal intestinal mucosa $(\mathrm{t}=6.232, \mathrm{P}<0.001)$. Furthermore, CCAT-1 RNA expression was significantly higher in the tumor tissue of colon cancer patients with hyperglycemia than in the tumor tissue of colon cancer patients with normal blood glucose levels $(\mathrm{t}=2.400$, $\mathrm{P}=0.035)$. There was no significant difference in CCAT-1 RNA expression in the distal normal intestinal mucosa between colon cancer patients with normal blood glucose levels and those with hyperglycemia $(\mathrm{t}=1.477, \mathrm{P}=0.168)$.

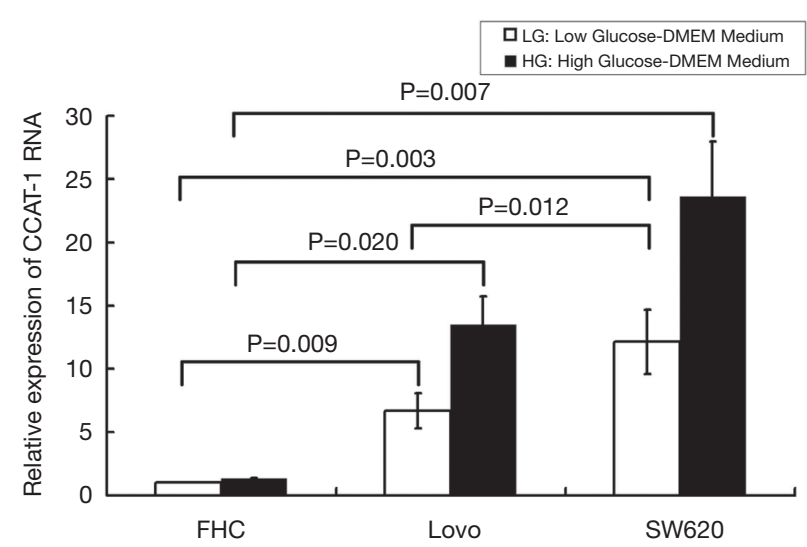

Figure 2 Expression of colon cancer-associated transcript-1 (CCAT-1) RNA in colon cancer cells and normal colon cells cultured under different glucose concentrations. The expression of CCAT-1 RNA in SW620 cells was significant. Therefore, the SW620 cell line was chosen as a stable transfected cell line. FHC, normal colon cell line (ATCC); LoVo, SW620: colon cancer cell line (ATCC).

\section{CCAT-1 RNA expression in different colon cancer cells and normal colon cells}

We used qPCR to verify the expression of CCAT-1 RNA in different colon cancer cells (LoVo and SW620) and normal colon cells (FHC). The results showed that the expression of CCAT-1 RNA in LoVo cells $(\mathrm{t}=13.414, \mathrm{P}=0.009)$ and SW620 cells $(\mathrm{t}=16.521, \mathrm{P}=0.007)$ cultured with high glucose was significantly higher than that in cells cultured with low glucose, but the difference in the expression of CCAT-1 RNA in FHC cells $(\mathrm{t}=0.586, \mathrm{P}=0.167)$ was not noticeable. Furthermore, the expression of CCAT-1 RNA in LoVo cells $(\mathrm{t}=7.028, \mathrm{P}=0.020)$ and SW620 cells $(\mathrm{t}=18.267$, $\mathrm{P}=0.003$ ) was significantly higher than that in FHC cells, and the expression of CCAT-1 RNA in SW620 cells was significantly higher than that in LoVo cells $(\mathrm{t}=8.957$, $\mathrm{P}=0.012$ ) (Figure 2). The results showed that the expression of CCAT-1 RNA in SW620 cells was significant. Thus, the SW620 cell line was chosen as a stable transfected cell line.

\section{CCAT-1 gene silencing in colon cancer cells}

We designed the shRNA of the CCAT-1 gene. The shRNA target sequence of the CCAT-1 gene is shown in Table 1 . SW620 cells were transfected, an appropriate shRNA was screened, shRNA was introduced, stable transfected cell 
Table 2 Primer sequence of CCAT-1 RNA for qPCR detection

\begin{tabular}{lcc}
\hline Primer & \multicolumn{1}{c}{ Sequence (5'-3') } & bp \\
\hline$\beta$-actin-1F & ACCACACCACACATTTCTCATAC & 179 \\
$\beta$-actin-1R & ACTGTCTCCTTCATCGTTCCA & \\
CCAT-1F & CCTACGCATACCTCTGCTTCT & 138 \\
CCAT-1R & GATTGCTCCTGTTTCCCTTT & \\
\hline
\end{tabular}

Table 3 Proportion of four groups SW620 cells in M1 stage (\%)

\begin{tabular}{lc}
\hline Group & The proportion of SW620 cells in M1 stage (\%) \\
\hline LG-EV & $12.73 \pm 1.807$ \\
LG-CCAT-1 $^{-}$ & $7.07 \pm 0.902$ \\
HG-EV & $31.70 \pm 1.572$ \\
HG-CCAT-1 $^{-}$ & $19.57 \pm 1.124$ \\
\hline
\end{tabular}

LG-EV, empty vector transfected colon cancer cells cultured with low glucose; LG-CCAT- ${ }^{-}$, CCAT-1 silenced colon cancer cells cultured with low glucose; HG-EV, empty vector transfected colon cancer cells cultured with high glucose; HGCCAT-1 ${ }^{-}$, CCAT-1 silenced colon cancer cells cultured with high glucose.

lines were selected, and the expression of $C C A T-1$ RNA was verified by qPCR. The primer sequence of $C C A T-1$ RNA is shown in Table 2.

The results showed that the CCAT-1 RNA expression in colon cancer cells transfected with shRNA $(111,291$, 331 , and 1,068 target sites) was significantly lower than that in cells transfected with an empty vector $(t=12.706$, $\mathrm{P}=0.006 ; \mathrm{t}=19.206, \mathrm{P}=0.003 ; \mathrm{t}=15.098, \mathrm{P}=0.004 ; \mathrm{t}=4.766$, $\mathrm{P}=0.041)$. The cells were divided into four groups: $C C A T$ 1 -silenced colon cancer cells cultured with high glucose (HG-CCAT-1 ${ }^{-}$), empty vector-transfected colon cancer cells cultured with high glucose (HG-EV), CCAT-1-silenced colon cancer cells cultured with low glucose (LG-CCAT-1 ${ }^{-}$), and empty vector-transfected colon cancer cells cultured with low glucose (LG-EV).

\section{Effect of CCAT-1 on the proliferation of colon cancer cells cultured with different glucose concentrations}

SW620 colon cancer cells were cultured with high and low glucose mediums for 48 hours. The proliferation of cells was detected via EDU cell proliferation analysis by flow cytometry. The results are shown in Table 3 and Figure 3.

The proportion of M1 phase cells was significantly lower in LG-CCAT-1 ${ }^{-}$and HG-CCAT-1 ${ }^{-}$groups than in LG-EV and HG-EV groups $(\mathrm{t}=10.883, \mathrm{P}=0.008$; $\mathrm{t}=8.154$, $\mathrm{P}=0.015$, respectively). Further, the proportion of $\mathrm{M} 1$ phase cells was significantly higher in $\mathrm{HG}-C C A T-1^{-}$and HG-EV groups than in LG-CCAT-1 ${ }^{-}$and LG-EV groups $(\mathrm{t}=17.279$, $\mathrm{P}=0.003 ; \mathrm{t}=10.387, \mathrm{P}=0.009$, respectively).

\section{Effect of CCAT-1 on the migration of colon cancer cells cultured with different glucose concentrations}

The Transwell migration assay was used to detect the migration ability of cancer cells. The results are shown in Figure 4.

The migration number of colon cancer cells was significantly lower in LG-CCAT-1 ${ }^{-}$and $\mathrm{HG}-C C A T-1^{-}$ groups than in LG-EV and HG-EV groups $(\mathrm{t}=92.000$, $\mathrm{P}<0.001 ; \mathrm{t}=37.000, \mathrm{P}=0.001)$, respectively. Furthermore, the migration number of colon cancer cells was significantly higher in HG-CCAT-1- ${ }^{-}$and HG-EV groups than in LG$C C A T-1^{-}$and $\mathrm{LG}-\mathrm{EV}$ groups $(\mathrm{t}=20.032, \mathrm{P}=0.002 ; \mathrm{t}=30.436$, $\mathrm{P}=0.001)$, respectively.

\section{Effect of CCAT-1 on glucose and lactic acid levels in colon cancer cells cultured with different glucose concentrations}

The levels of glucose and lactic acid were measured by ELISA, following the instructions mentioned in the corresponding kits, and the absorbance value was observed. The results are shown in Figure 5.

The results showed that glucose and lactic acid levels in the LG-CCAT-1 ${ }^{-}$group were significantly lower than those in the LG-EV group ( $\mathrm{t}=24.757, \mathrm{P}=0.002 ; \mathrm{t}=23.852$, $\mathrm{P}=0.002)$. Furthermore, glucose and lactic acid levels in $\mathrm{HG}-C C A T-1^{-}$the group were significantly lower than those in the HG-EV group $(\mathrm{t}=146.000, \mathrm{P}<0.001 ; \mathrm{t}=32.505$, $\mathrm{P}=0.001)$. Finally, glucose and lactic acid levels in the HGEV group were significantly higher than those in the LGEV group $(\mathrm{t}=271.000, \mathrm{P}<0.001 ; \mathrm{t}=43.600, \mathrm{P}=0.001)$.

\section{Effect of CCAT-1 on the expressions of glycolytic enzyme proteins and mRNAs in colon cancer cells cultured with different glucose concentrations}

The protein expressions of LDH-A, PKM2, and HK2 were detected by Western blotting. The results are shown in Figure 6.

The results of Western blotting showed that the protein expressions of LDH-A $(\mathrm{t}=51.570, \mathrm{P}<0.001 ; \mathrm{t}=105.325$, 
LG-EV

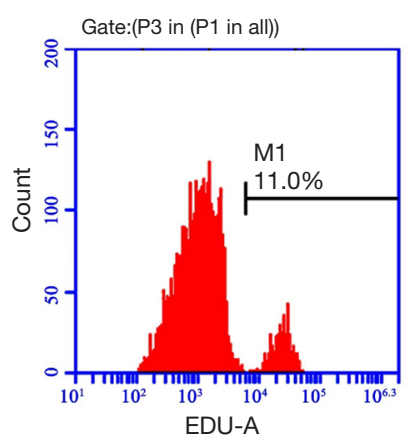

LG-CCAT-1

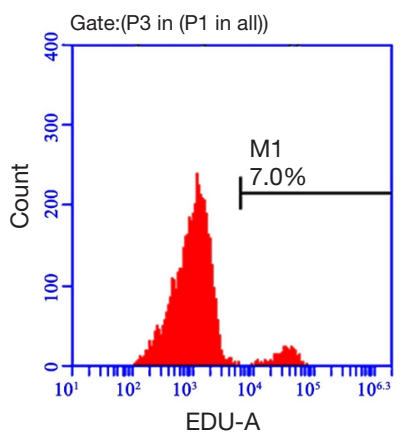

HG-EV

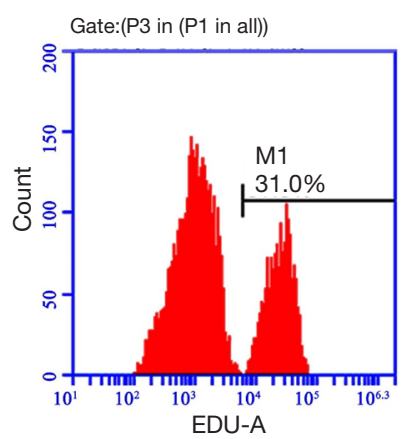

HG-CCAT-1

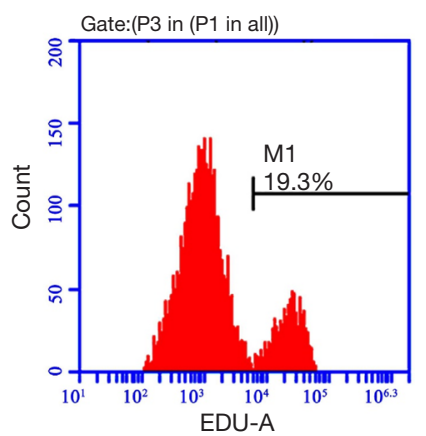

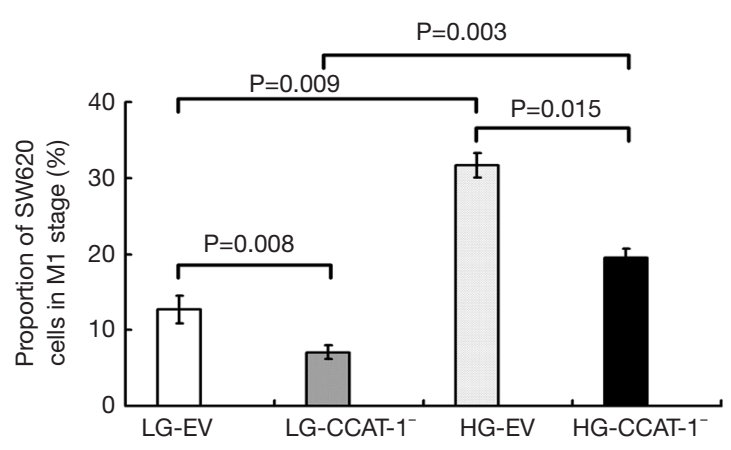

Figure 3 The effect of colon cancer-associated transcript-1 (CCAT-1) on the proliferation of colon cancer cells cultured under different glucose concentrations. The proportion of M1 phase cells was significantly lower in LG-CCAT-1 ${ }^{-}$and $\mathrm{HG}-C C A T-1^{-}$groups than in LG-EV and HG-EV groups $(\mathrm{t}=10.883, \mathrm{P}=0.008 ; \mathrm{t}=8.154, \mathrm{P}=0.015$, respectively). Furthermore, the proportion of $\mathrm{M} 1$ phase cells was significantly higher in HG-CCAT-1 ${ }^{-}$and HG-EV groups than in LG-CCAT-1 ${ }^{-}$and $\mathrm{LG}-\mathrm{EV}$ groups $(\mathrm{t}=17.279, \mathrm{P}=0.003$; $\mathrm{t}=10.387$, $\mathrm{P}=0.009$, respectively). LG-EV, Empty vector transfected colon cancer cells cultured with low glucose; LG-CCAT-1'- CCAT-1 silenced colon cancer cells cultured with low glucose; HG-EV, empty vector transfected colon cancer cells cultured with high glucose; HG-CCAT-1 ${ }^{-}$, CCAT-1 silenced colon cancer cells cultured with high glucose.

$\mathrm{P}<0.001), \mathrm{PKM} 2(\mathrm{t}=37.344, \mathrm{P}=0.001 ; \mathrm{t}=462.343, \mathrm{P}<0.001)$, and HK2 ( $\mathrm{t}=23.666, \mathrm{P}=0.002 ; \mathrm{t}=614.798, \mathrm{P}<0.001)$ in the $\mathrm{LG}-C C A T-1^{-}$group were significantly lower than those in the LG-EV and HG-EV groups. Further, the protein expressions of LDH-A $(\mathrm{t}=92.661, \mathrm{P}<0.001), \mathrm{PKM} 2$ $(\mathrm{t}=126.816, \mathrm{P}<0.001)$, and HK2 $(\mathrm{t}=16.753, \mathrm{P}=0.004)$ in the HG-CCAT-1 ${ }^{-}$group were significantly higher than those in the LG-CCAT-1 $1^{-}$group, and the protein expressions of LDH-A ( $\mathrm{t}=115.943, \mathrm{P}<0.001), \mathrm{PKM} 2(\mathrm{t}=6.752, \mathrm{P}=0.022)$, and HK2 ( $\mathrm{t}=288.004, \mathrm{P}<0.001)$ in the $\mathrm{HG}-\mathrm{EV}$ group were significantly higher than those in the LG-EV group.

The mRNA expressions of LDH-A, PKM2, and HK2 were detected by qPCR. The results are shown in Figure 7.

The results of qPCR showed that the mRNA expressions of LDH-A ( $\mathrm{t}=15.107, \mathrm{P}=0.004), \mathrm{PKM} 2$ ( $\mathrm{t}=23.705, \mathrm{P}=0.002)$, and HK2 $(\mathrm{t}=26.484, \mathrm{P}=0.001)$ in the $\mathrm{LG}-C C A T-1^{-}$group were significantly lower than those in the LG-EV group. The expressions of mRNA of LDH-A $(t=9.018, P=0.012)$,
PKM2 ( $\mathrm{t}=9.005, \mathrm{P}=0.012)$, and HK2 ( $\mathrm{t}=9.139, \mathrm{P}=0.012)$ in HG-CCAT- $1^{-}$the group was significantly lower than those in the HG-EV group. Further, the mRNA expressions of LDH-A ( $\mathrm{t}=8.728, \mathrm{P}=0.013)$, PKM2 $(\mathrm{t}=14.073, \mathrm{P}=0.005)$, and HK2 $(\mathrm{t}=17.395, \mathrm{P}=0.003)$ in the $\mathrm{HG}-C C A T-1^{-}$group were significantly higher than those in the LG-CCAT-1group; the mRNA expressions of LDH-A $(t=3.582$, $\mathrm{P}=0.070)$ and PKM2 ( $\mathrm{t}=4.012, \mathrm{P}=0.057)$ in the HG-EV group were significantly higher than those in the LG-EV group. Finally, there was no significant difference in the mRNA expression of HK2 ( $\mathrm{t}=6.754, \mathrm{P}=0.021)$ between HGEV and LG-EV groups.

Effect of CCAT-1 on the protein and mRNA expressions of apoptosis genes in colon cancer cells under different glucose concentrations

Western blotting was used to determine the protein 

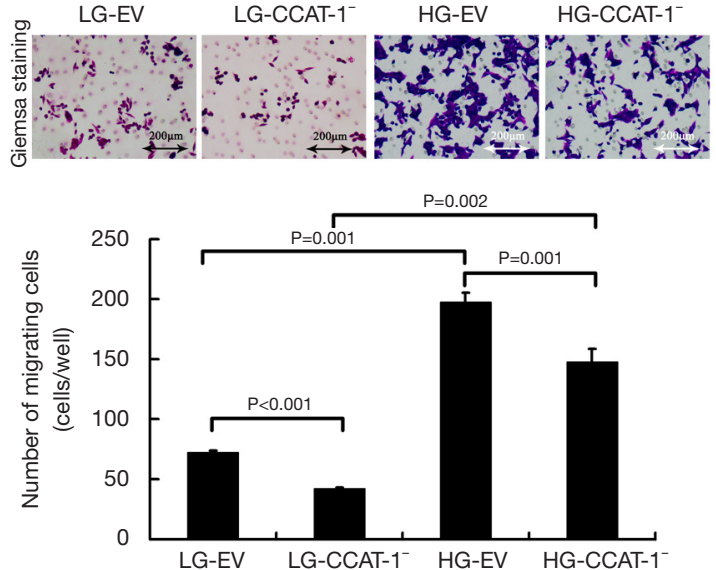

Figure 4 The effect of colon cancer-associated transcript-1 (CCAT-1) on the migration of colon cancer cells cultured with different glucose concentrations. The migration number of colon cancer cells was significantly lower in LG-CCAT-1 ${ }^{-}$and HGCCAT-1 $1^{-}$groups than in LG-EV and HG-EV groups ( $\mathrm{t}=92.000$, $\mathrm{P}<0.001 ; \mathrm{t}=37.000, \mathrm{P}=0.001$, respectively). Furthermore, the migration number of colon cancer cells was significantly higher in HG-CCAT-1 ${ }^{-}$and HG-EV groups than in LG-CCAT-1 ${ }^{-}$and LG$\mathrm{EV}$ groups $(\mathrm{t}=20.032, \mathrm{P}=0.002 ; \mathrm{t}=30.436, \mathrm{P}=0.001$, respectively). LG-EV, empty vector transfected colon cancer cells cultured with low glucose; LG-CCAT-1 ${ }^{-}$, CCAT-1 silenced colon cancer cells cultured with low glucose; HG-EV, empty vector transfected colon cancer cells cultured with high glucose; HG-CCAT-1 ${ }^{-}$, CCAT-1 silenced colon cancer cells cultured with high glucose. expressions of Bcl-2 and Bax. The results are shown in Figure 8.

The Western blotting results showed that the protein expressions of Bcl-2 were significantly lower $(t=4.666$, $\mathrm{P}=0.043)$ and $\mathrm{BAX}$ were significantly higher $(\mathrm{t}=6.145$, $\mathrm{P}=0.025)$ in the LG-CCAT-1- $1^{-}$group than in the LG-EV group; the protein expressions of Bcl-2 were significantly lower $(\mathrm{t}=13.899, \mathrm{P}=0.005)$ and $\mathrm{Bax}$ was significantly higher $(\mathrm{t}=389.730, \mathrm{P}<0.001)$ in the $\mathrm{HG}-C C A T-1^{-}$group than in the HG-EV group. Further, the protein expressions of Bcl2 were significantly higher $(\mathrm{t}=7.641, \mathrm{P}=0.017)$, and $\mathrm{Bax}$ was significantly lower $(\mathrm{t}=27.601, \mathrm{P}=0.001)$ in the HG-CCAT-1 group than in the LG-CCAT-1 $1^{-}$group. Finally, the protein expressions of Bcl-2 were significantly higher $(t=15.348$, $\mathrm{P}=0.004)$, and Bax was significantly lower $(\mathrm{t}=5.971, \mathrm{P}=0.027)$ in the HG-EV group than in the LG-EV group.

The mRNA expressions of Bcl-2 and Bax were detected by $\mathrm{qPCR}$. The results are shown in Figure 9.

The mRNA expression of Bcl-2 decreased ( $t=13.629$, $\mathrm{P}=0.005)$, and $\mathrm{Bax}$ increased $(\mathrm{t}=5.257, \mathrm{P}=0.034)$ significantly in $\mathrm{LG}-C C A T-1^{-}$group compared with that in the LGEV group. The mRNA expression of Bcl-2 decreased $(\mathrm{t}=18.301, \mathrm{P}=0.003)$, and Bax increased $(\mathrm{t}=14.658, \mathrm{P}=0.005)$ significantly in the HG-CCAT-1- $1^{-}$group compared with that in HG-EV group. Furthermore, the mRNA expression of Bcl-2 increased $(t=13.408, P=0.006)$, and Bax decreased
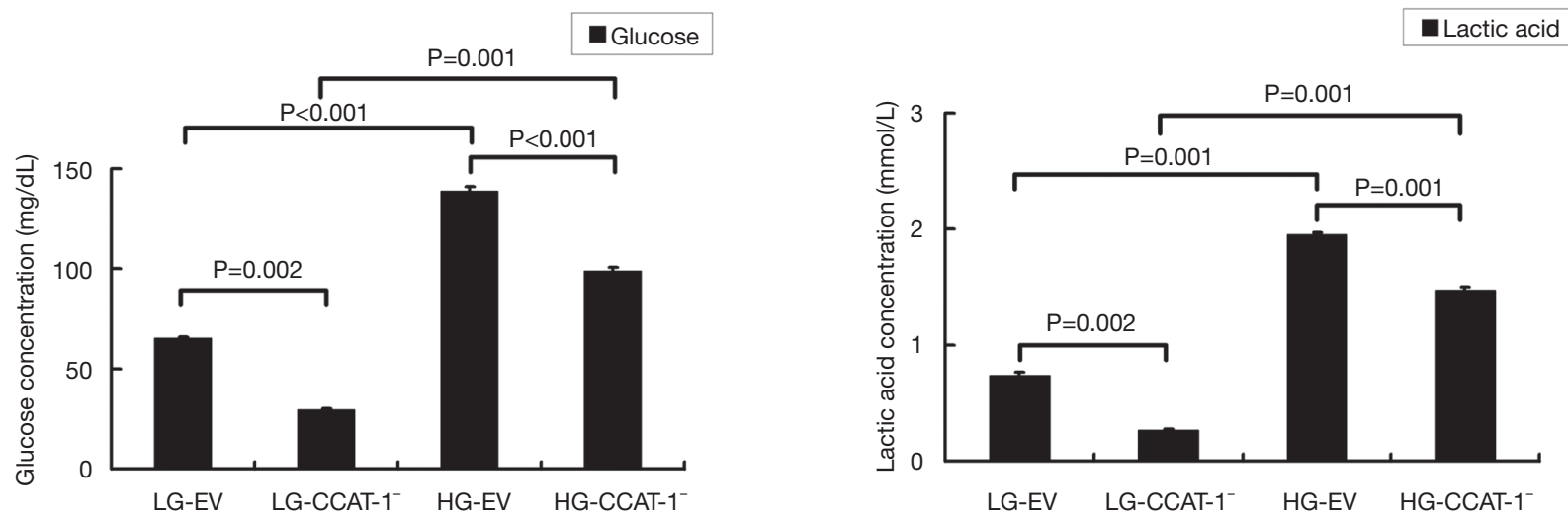

Figure 5 The effect of colon cancer-associated transcript-1 (CCAT-1) on glucose and lactic acid levels in colon cancer cells cultured under different glucose concentrations. The glucose and lactic acid levels in the LG-CCAT-1 ${ }^{-}$group were significantly lower than those in the LG-EV group ( $\mathrm{t}=24.757, \mathrm{P}=0.002 ; \mathrm{t}=23.852, \mathrm{P}=0.002)$. The glucose and lactic acid levels in HG-CCAT-1 ${ }^{-}$the group were significantly lower than those in the HG-EV group $(\mathrm{t}=146.000, \mathrm{P}<0.001 ; \mathrm{t}=32.505, \mathrm{P}=0.001)$. The glucose and lactic acid levels in the HG-EV group were significantly higher than those in the LG-EV group $(\mathrm{t}=271.000, \mathrm{P}<0.001 ; \mathrm{t}=43.600, \mathrm{P}=0.001)$. LG-EV, empty vector transfected colon cancer cells cultured with low glucose; LG-CCAT-1 ${ }^{-}$, CCAT-1 silenced colon cancer cells cultured with low glucose; HG-EV, empty vector transfected colon cancer cells cultured with high glucose; HG-CCAT-1 ${ }^{-}$, CCAT-1 silenced colon cancer cells cultured with high glucose. 

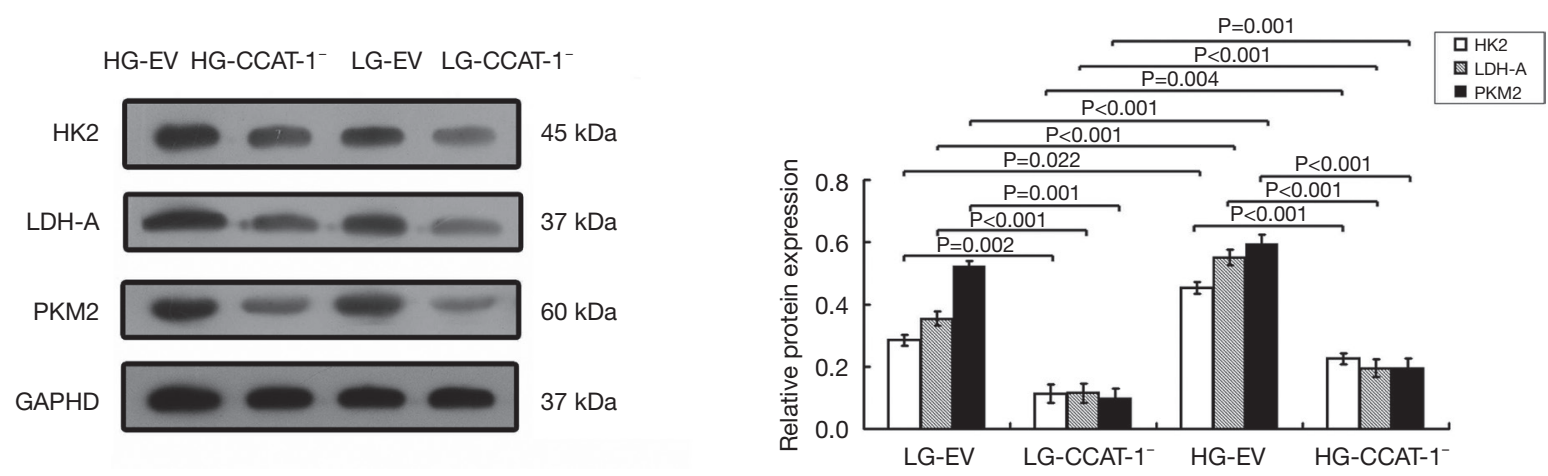

Figure 6 The effect of colon cancer-associated transcript-1 (CCAT-1) on glycolytic enzymes' protein expression in colon cancer cells cultured under different glucose concentrations. The protein expressions of LDH-A ( $\mathrm{t}=51.570, \mathrm{P}<0.001 ; \mathrm{t}=105.325, \mathrm{P}<0.001), \mathrm{PKM} 2$ ( $\mathrm{t}=37.344, \mathrm{P}=0.001 ; \mathrm{t}=462.343, \mathrm{P}<0.001)$, and HK2 ( $\mathrm{t}=23.666, \mathrm{P}=0.002 ; \mathrm{t}=614.798, \mathrm{P}<0.001)$ in the LG-CCAT-1 ${ }^{-}$group were significantly lower than those in the LG-EV and HG-EV groups. Furthermore, the protein expressions of LDH-A ( $\mathrm{t}=92.661, \mathrm{P}<0.001), \mathrm{PKM} 2(\mathrm{t}=126.816$, $\mathrm{P}<0.001)$, and HK2 ( $\mathrm{t}=16.753, \mathrm{P}=0.004)$ in the HG-CCAT-1 $1^{-}$group were significantly higher than those in the LG-CCAT-1 ${ }^{-}$group, and the protein expressions of LDH-A ( $\mathrm{t}=115.943, \mathrm{P}<0.001)$, PKM2 $(\mathrm{t}=6.752, \mathrm{P}=0.022)$, and HK2 $(\mathrm{t}=288.004, \mathrm{P}<0.001)$ in the HG-EV group were significantly higher than those in the LG-EV group. HG-EV, empty vector transfected colon cancer cells cultured with high glucose; HGCCAT-1 ${ }^{-}$, CCAT-1 silenced colon cancer cells cultured with low glucose; LG-EV, empty vector transfected colon cancer cells cultured with low glucose; LG-CCAT-1 ${ }^{-}$, CCAT-1 silenced colon cancer cells cultured with low glucose.

( $\mathrm{t}=11.893, \mathrm{P}=0.007)$ significantly in the $\mathrm{HG}-C C A T-1^{-}$group compared with that in the LG-CCAT-1 ${ }^{-}$group. Finally, the mRNA expression of Bcl-2 increased ( $\mathrm{t}=13.629, \mathrm{P}=0.005)$, and Bax decreased ( $\mathrm{t}=5.257, \mathrm{P}=0.034)$ significantly in the HG-EV group compared with that in the LG-EV group.

\section{Effect of CCAT-1 on the protein expression of EMT markers in colon cancer cells cultured with different glucose concentrations}

Western blotting was used to detect the protein expression of E-cadherin, ZO-1, N-cadherin, and vimentin. The results are shown in Figure 10.

The Western blotting results showed that the protein expression of ZO-1 was significantly higher $(\mathrm{t}=33.050$, $\mathrm{P}=0.019)$ in the LG-CCAT-1 $1^{-}$group than in the LG$\mathrm{EV}$ group, but there was no significant difference in the expressions of $\mathrm{E}$-cadherin $(\mathrm{t}=4.725, \mathrm{P}=0.133)$, N-Cadherin $(\mathrm{t}=4.577, \mathrm{P}=0.137)$, and vimentin $(\mathrm{t}=3.146, \mathrm{P}=0.196)$ between these groups. Furthermore, the protein expressions of E-cadherin and ZO-1 were significantly higher $(\mathrm{t}=31.079$, $\mathrm{P}=0.020 ; \mathrm{t}=143.200, \mathrm{P}=0.004)$, and those of $\mathrm{N}$-cadherin and vimentin were significantly lower $(\mathrm{t}=14.491, \mathrm{P}=0.044$; $\mathrm{t}=16.853, \mathrm{P}=0.038)$ in the HG-CCAT-1 ${ }^{-}$group than in the HG-EV group. The protein expression of ZO-1 was significantly lower $(\mathrm{t}=16.768, \mathrm{P}=0.038)$ and vimentin was significantly higher $(\mathrm{t}=24.846, \mathrm{P}=0.026)$ in $\mathrm{HG}-C C A T-1^{-}$ group than in the LG-CCAT-1 $1^{-}$group, but the expressions of $\mathrm{E}$-cadherin and $\mathrm{N}$-cadherin $(\mathrm{t}=1.740, \mathrm{P}=0.332 ; \mathrm{t}=3.780$, $\mathrm{P}=0.165$ ) showed no significant difference between these groups. Finally, the protein expression of $\mathrm{N}$-cadherin was significantly higher $(\mathrm{t}=34.353, \mathrm{P}=0.019)$ in the HG-EV group than in the LG-EV group, but the expressions of E-cadherin ( $\mathrm{t}=5.102, \mathrm{P}=0.123), \mathrm{ZO}-1 \quad(\mathrm{t}=12.783, \mathrm{P}=0.054)$, and vimentin $(\mathrm{t}=4.815, \mathrm{P}=0.130)$ were not significantly different between these groups.

\section{Effect of CCAT-1 on the expression of PI3K/Akt/C-MYC patbway in colon cancer cells under different glucose concentrations}

The expressions of PI3K, Akt, C-MYC, and phosphorylated proteins were detected by Western blotting. The results are shown in Figure 11.

There was no significant difference between the expression levels of P-PI3K, P-AKT, and P-C-MYC (LG$\mathrm{EV}: \mathrm{t}=3.545, \mathrm{P}=0.175 ; \mathrm{t}=9.004, \mathrm{P}=0.070 ; \mathrm{t}=4.405, \mathrm{P}=0.142$; LG-CCAT-1 ${ }^{-}: \mathrm{t}=10.619, \mathrm{P}=0.060 ; \mathrm{t}=5.307, \mathrm{P}=0.119 ; \mathrm{t}=5.234$, $\mathrm{P}=0.120$; HG-EV: $\mathrm{t}=1.216, \mathrm{P}=0.438 ; \mathrm{t}=0.521, \mathrm{P}=0.694$; $\mathrm{t}=0.203, \mathrm{P}=0.873$ ) and those of their unphosphorylated proteins in LG-EV, LG-CCAT-1-1 , and HG-EV groups. $\mathrm{P}$-Akt expression level decreased significantly $(\mathrm{t}=61.036$, 


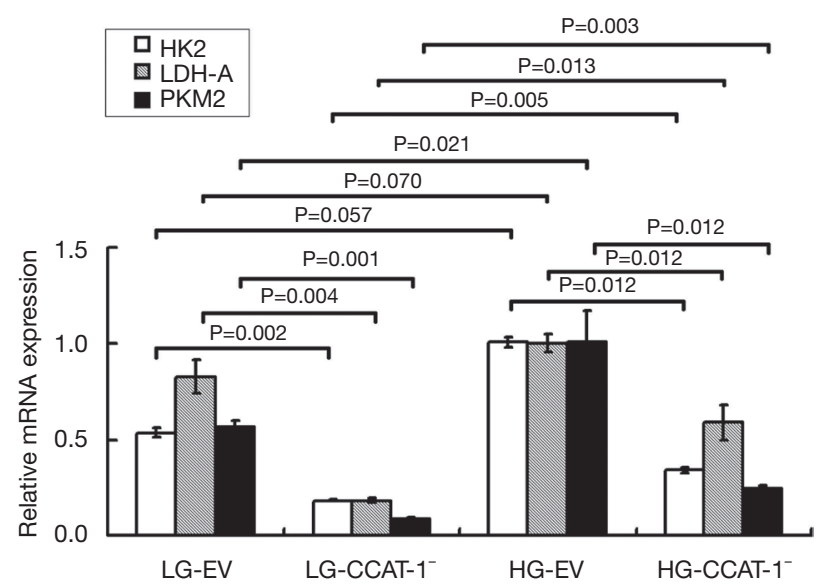

Figure 7 The effect of colon cancer-associated transcript-1 (CCAT-1) on the mRNA expression of glycolytic enzymes in colon cancer cells cultured under different glucose concentrations. The mRNA expressions of LDH-A ( $\mathrm{t}=15.107, \mathrm{P}=0.004)$, PKM2 $(\mathrm{t}=23.705, \mathrm{P}=0.002)$, and HK2 $(\mathrm{t}=26.484, \mathrm{P}=0.001)$ in the $\mathrm{LG}-$ CCAT-1 $1^{-}$group were significantly lower than those in the LGEV group. The mRNA expressions of LDH-A ( $\mathrm{t}=9.018, \mathrm{P}=0.012)$, PKM2 ( $\mathrm{t}=9.005, \mathrm{P}=0.012)$, and HK2 $(\mathrm{t}=9.139, \mathrm{P}=0.012)$ in the HG$C C A T-1^{-}$group were significantly lower than those in the HG-EV group. Furthermore, the mRNA expressions of LDH-A $(\mathrm{t}=8.728$, $\mathrm{P}=0.013)$, PKM2 $(\mathrm{t}=14.073, \mathrm{P}=0.005)$, and HK2 $(\mathrm{t}=17.395$, $\mathrm{P}=0.003)$ in the HG-CCAT-1 ${ }^{-}$group were significantly higher than those in the LG-CCAT-1 $1^{-}$group; the mRNA expressions of LDH-A ( $\mathrm{t}=3.582, \mathrm{P}=0.070)$ and PKM2 $(\mathrm{t}=4.012, \mathrm{P}=0.057)$ in the HG-EV group were significantly higher than those in the LGEV group. LG-EV, empty vector transfected colon cancer cells cultured with low glucose; LG-CCAT-1 ${ }^{-}$, CCAT-1 silenced colon cancer cells cultured with low glucose; HG-EV, empty vector transfected colon cancer cells cultured with high glucose; HGCCAT-1 ${ }^{-}$, CCAT-1 silenced colon cancer cells cultured with high glucose.

$\mathrm{P}=0.010)$ compared with the expression level of its unphosphorylated antibody in the HG-CCAT-1 $1^{-}$group, but there was no significant difference in the expression levels of P-PI3K and P-C-MYC ( $\mathrm{t}=3.538, \mathrm{P}=0.175 ; \mathrm{t}=5.316$, $\mathrm{P}=0.118)$ in the HG-CCAT $-1^{-}$group. The expression levels of P-PI3K and P-C-MYC were significantly lower in the LG-CCAT $-1^{-}$group than in the LG-EV group ( $\mathrm{t}=46.442$, $\mathrm{P}=0.014 ; \mathrm{t}=42.208, \mathrm{P}=0.015)$, whereas the expression levels of PI3K, Akt, p-Akt, and C-MYC showed no significant difference $(\mathrm{t}=1.639, \mathrm{P}=0.349 ; \mathrm{t}=2.060, \mathrm{P}=0.288 ; \mathrm{t}=2.328$, $\mathrm{P}=0.258 ; \mathrm{t}=5.542, \mathrm{P}=0.115)$ between these groups.
Compared with the HG-EV group, the HG-CCAT-1 ${ }^{-}$ group showed significantly lower expression levels of P-AKT $(t=20.136, P=0.032)$, whereas no significant difference was observed in the expression levels of PI3K, P-PI3K, AKT, C-MYC, and P-C-MYC between these groups $(t=0.723$, $\mathrm{P}=0.602 ; \mathrm{t}=4.357, \mathrm{P}=0.144 ; \mathrm{t}=0.374, \mathrm{P}=0.772 ; \mathrm{t}=0.045$, $\mathrm{P}=0.971 ; \mathrm{t}=5.177, \mathrm{P}=0.121)$. Furthermore, compared with the LG-CCAT-1- ${ }^{-}$group, the HG-CCAT-1- ${ }^{-}$group showed significantly higher expression levels of P-C-MYC $(t=68.504, P=0.009)$, whereas the expression levels of PI3K, P-PI3K, AKT, P-AKT, and C-MYC showed no significant difference between these groups $(t=1.625, P=0.350$; $\mathrm{t}=9.573, \mathrm{P}=0.066 ; \mathrm{t}=2.546, \mathrm{P}=0.238 ; \mathrm{t}=3.950, \mathrm{P}=0.158$; $\mathrm{t}=4.088, \mathrm{P}=0.153)$. Finally, the expression levels of PI3K, P-PI3K, AKT, P-AKT, C-MYC, and P-C-MYC showed no significant difference between LG-EV and HG-EV groups $(\mathrm{t}=3.151, \mathrm{P}=0.196 ; \mathrm{t}=2.415, \mathrm{P}=0.250 ; \mathrm{t}=0.584, \mathrm{P}=0.663$; $\mathrm{t}=3.527, \mathrm{P}=0.176 ; \mathrm{t}=0.033, \mathrm{P}=0.979 ; \mathrm{t}=4.068, \mathrm{P}=0.153)$.

\section{Effect of CCAT-1 on the volume of colon cancer xenografts in nude mice with different blood glucose concentrations}

Four weeks after tumor cell transplantation, the nude mice in each group were dissected. The tumor bodies were dissected, and the volume was measured using a Vernier caliper. The result is shown in Table 4 and Figure 12.

The tumor volume of nude mice was significantly lower in the NG-CCAT-1- group than in the NG-EV group $(\mathrm{t}=5.257, \mathrm{P}=0.034)$; further, the tumor volume of nude mice was significantly lower in the HG-CCAT-1 $1^{-}$group than in the HG-EV group ( $\mathrm{t}=4.892, \mathrm{P}=0.039)$; no significant difference was observed in the tumor volume of nude mice in HG-CCAT-1 $1^{-}$and NG-CCAT-1 $1^{-}$groups ( $\mathrm{t}=2.311$, $\mathrm{P}=0.147)$. Finally, the tumor volume of nude mice in the HG-EV group was significantly higher than that in the NG-EV group $(\mathrm{t}=10.231, \mathrm{P}=0.009)$.

\section{Effect of CCAT-1 on serum glucose, lactic acid, and insulin levels in nude mice with different blood glucose concentrations}

TBA-40 automatic biochemical analyzer and ELISA biochemical kit were used to detect the content of glucose, lactic acid, and insulin in the serum samples of nude mice with different blood glucose levels. The results are shown in Figure 13.

The levels of serum glucose $(\mathrm{t}=13.369, \mathrm{P}=0.001)$ and 

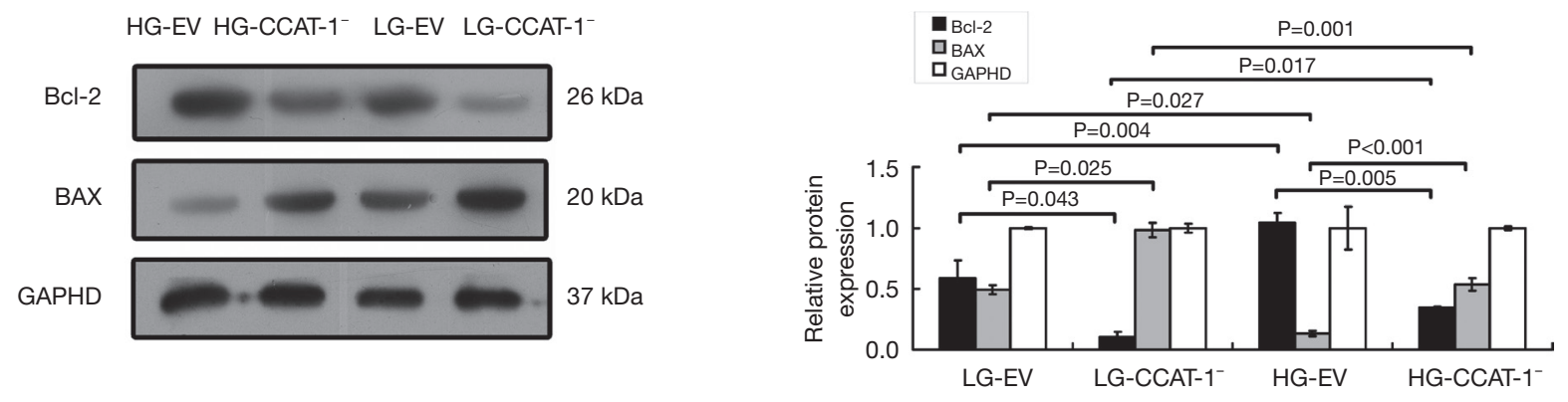

Figure 8 The effect of colon cancer-associated transcript-1 (CCAT-1) on the protein expression of Bc12 and Bax in colon cancer cells cultured under different glucose concentrations. The protein expressions of Bcl-2 were significantly lower $(\mathrm{t}=4.666, \mathrm{P}=0.043)$ and $\mathrm{BAX}$ were significantly higher $(\mathrm{t}=6.145, \mathrm{P}=0.025)$ in the $\mathrm{LG}-C C A T-1^{-}$group than in the LG-EV group; the protein expressions of Bcl-2 were significantly lower $(\mathrm{t}=13.899, \mathrm{P}=0.005)$ and Bax was significantly higher $(\mathrm{t}=389.730, \mathrm{P}<0.001)$ in the HG-CCAT- $1^{-}$group than in the HGEV group. Furthermore, the protein expressions of Bcl-2 were significantly higher ( $\mathrm{t}=7.641, \mathrm{P}=0.017)$, and Bax was significantly lower $(\mathrm{t}=27.601, \mathrm{P}=0.001)$ in the HG-CCAT-1- ${ }^{-}$group than in the LG-CCAT-1- group. Finally, the protein expressions of Bcl-2 were significantly higher ( $\mathrm{t}=15.348, \mathrm{P}=0.004)$, and Bax was significantly lower $(\mathrm{t}=5.971, \mathrm{P}=0.027$ ) in the HG-EV group than in the LG-EV group. HG-EV, empty vector transfected colon cancer cells cultured with high glucose; HG-CCAT-1 ${ }^{-}$, CCAT-1-silenced colon cancer cells cultured with low glucose; LG-EV, empty vector transfected colon cancer cells cultured with low glucose; LG-CCAT-1 $1^{-}$, CCAT-1 ${ }^{-}$silenced colon cancer cells cultured with low glucose.

insulin ( $\mathrm{t}=5.571, \mathrm{P}=0.011)$ were significantly lower in the NG-CCAT-1 ${ }^{-}$group than in the NG-EV group, whereas no significant difference was observed in the levels of lactic acid between these groups $(t=3.445, P=0.075)$; the levels of serum glucose $(\mathrm{t}=17.689, \mathrm{P}<0.001)$, lactic acid $(\mathrm{t}=5.033, \mathrm{P}=0.037)$, and insulin $(\mathrm{t}=5.817, \mathrm{P}=0.010)$ were significantly lower in the HG-CCAT-1 $1^{-}$group than in the HG-EV group. Further, the levels of serum glucose $(\mathrm{t}=28.352, \mathrm{P}<0.001)$, lactic acid $(\mathrm{t}=4.539, \mathrm{P}=0.045)$, and insulin $(\mathrm{t}=19.024, \mathrm{P}<0.001)$ were significantly higher in the HG-CCAT-1 $1^{-}$group than in the NG-CCAT-1 $1^{-}$group. The levels of serum glucose $(\mathrm{t}=19.575, \mathrm{P}<0.001)$ and insulin $(\mathrm{t}=8.560, \mathrm{P}=0.003)$ were significantly higher in the HG-EV group than in the NG-EV group, whereas no significant difference was observed in the levels of lactic acid between these two groups $(\mathrm{t}=1.456, \mathrm{P}=0.283)$.

\section{Effect of CCAT-1 on the expression of EMT marker protein in nude mice with different blood glucose concentrations}

The expression levels of E-cadherin, ZO-1, N-cadherin, and vimentin were detected by Western blotting. The results are shown in Figure 14.

The expression level of $\mathrm{N}$-cadherin was significantly lower in the LG-CCAT-1 ${ }^{-}$group than in the LG-EV group $(\mathrm{t}=17.114, \mathrm{P}=0.037)$, whereas no significant difference was observed in the expression levels of E-cadherin, ZO-1, and vimentin ( $\mathrm{t}=10.945, \mathrm{P}=0.058 ; \mathrm{t}=10.943, \mathrm{P}=0.058 ; \mathrm{t}=8.016$, $\mathrm{P}=0.079)$ between these two groups. The expression level of ZO-1 was significantly higher $(\mathrm{t}=40.082, \mathrm{P}=0.016)$ and vimentin was significantly lower $(\mathrm{t}=28.320, \mathrm{P}=0.022)$ in the HG-CCAT-1 $1^{-}$group than in the HG-EV group, and no significant differences in the expression levels of $\mathrm{E}$-cadherin and $\mathrm{N}$-Cadherin $(\mathrm{t}=4.029, \mathrm{P}=0.155 ; \mathrm{t}=4.493, \mathrm{P}=0.139)$ were observed between these two groups. The expression level of ZO-1 was significantly lower $(\mathrm{t}=18.002, \mathrm{P}=0.035)$ in the HG-CCAT-1 ${ }^{-}$group than in the $\mathrm{LG}-C C A T-1^{-}$group, whereas E-cadherin, N-Cadherin, and Vimentin expression levels $(\mathrm{t}=1.467, \mathrm{P}=0.381 ; \mathrm{t}=6.582, \mathrm{P}=0.096 ; \mathrm{t}=0.390$, $\mathrm{P}=0.763$ ) showed no significant differences between these two groups. The expression levels of E-cadherin, ZO-1, $\mathrm{N}$-Cadherin, and Vimentin $(\mathrm{t}=5.445, \mathrm{P}=0.116 ; \mathrm{t}=3.496$, $\mathrm{P}=0.177 ; \mathrm{t}=3.343, \mathrm{P}=0.185 ; \mathrm{t}=4.417, \mathrm{P}=0.142$ ) showed no significant differences between LG-EV and HG-EV groups.

\section{Effect of CCAT-1 on PI3K/Akt/C-MYC pathway in nude mice with different blood glucose concentrations}

The protein expression levels of PI3K, Akt, C-MYC, and their phosphorylated proteins in transplanted tumors of nude mice with different blood glucose concentrations were detected by Western blotting. The results are shown in Figure 15.

No significant difference was observed between the 


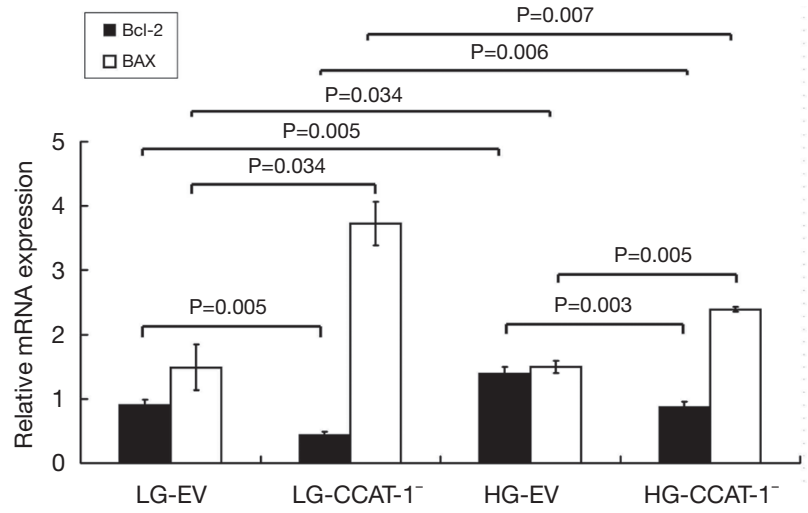

Figure 9 The effect of colon cancer-associated transcript-1 (CCAT-1) on the mRNA expressions of $\mathrm{Bcl} 2$ and $\mathrm{Bax}$ in colon cancer cells cultured under different glucose concentrations. The mRNA expressions of Bcl-2 decreased ( $\mathrm{t}=13.629, \mathrm{P}=0.005)$, and Bax increased $(\mathrm{t}=5.2577, \mathrm{P}=0.034)$ significantly in LG-CCAT-1 group compared with those in the LG-EV group. The mRNA expressions of Bcl-2 decreased ( $\mathrm{t}=18.301, \mathrm{P}=0.003)$, and $\mathrm{Bax}$ increased $(\mathrm{t}=14.658, \mathrm{P}=0.005)$ significantly in the HG-CCAT-1 group compared with those in the HG-EV group. Furthermore, the mRNA expressions of Bcl-2 increased ( $\mathrm{t}=13.408, \mathrm{P}=0.006)$, and Bax decreased $(\mathrm{t}=11.893, \mathrm{P}=0.007)$ significantly in the $\mathrm{HG}^{-}$ $C C A T-1^{-}$group compared with those in the LG-CCAT-1 ${ }^{-}$group. Finally, the mRNA expressions of Bcl-2 increased ( $\mathrm{t}=13.629$, $\mathrm{P}=0.005)$, and Bax decreased $(\mathrm{t}=5.257, \mathrm{P}=0.034)$ significantly in the HG-EV group compared with those in the LG-EV group. LG-EV, empty vector transfected colon cancer cells cultured with low glucose; LG-CCAT-1 ${ }^{-}$, CCAT-1 silenced colon cancer cells cultured with low glucose; HG-EV, empty vector transfected colon cancer cells cultured with high glucose; HG-CCAT-1 ${ }^{-}$, CCAT-1 silenced colon cancer cells cultured with high glucose.

expression levels of P-PI3K, P-AKT, and P-C-MYC and their unphosphorylated proteins (LG-EV: $\mathrm{t}=11.453$, $\mathrm{P}=0.055 ; \mathrm{t}=1.034, \mathrm{P}=0.489 ; \mathrm{t}=7.725, \mathrm{P}=0.082$; LGCCAT $-1^{-}: \mathrm{t}=6.880, \mathrm{P}=0.092 ; \mathrm{t}=8.056, \mathrm{P}=0.079 ; \mathrm{t}=12.145$, $\mathrm{P}=0.052 ; \mathrm{HG}-\mathrm{EV}: \mathrm{t}=6.369, \mathrm{P}=0.099 ; \mathrm{t}=0.088, \mathrm{P}=0.944$; $\mathrm{t}=11.026, \mathrm{P}=0.053)$ in LG-EV, LG-CCAT-1 ${ }^{-}$, and HG-EV groups. No significant difference was observed between the expression of P-PI3K and its unphosphorylated antibody ( $\mathrm{t}=6.616, \mathrm{P}=0.095$ ) in the $\mathrm{HG}-C C A T-1^{-}$group, but $\mathrm{p}$-Akt and $\mathrm{p}$-C-MYC levels were significantly lower than their unphosphorylated counterparts $(\mathrm{t}=40.486$, $\mathrm{P}=0.016 ; \mathrm{t}=67.239, \mathrm{P}=0.009)$ in the HG-CCAT $-1^{-}$group. Furthermore, the expression levels of P-AKT $(\mathrm{t}=37.844$, $\mathrm{P}=0.017)$ and $\mathrm{P}-\mathrm{C}-\mathrm{MYC}(\mathrm{t}=23.894, \mathrm{P}=0.027)$ were significantly lower in the HG-CCAT-1 $1^{-}$group than in the LG-EV group, whereas no significant difference was observed in the expression levels of PI3K, P-PI3K, AKT, and $\mathrm{C}-\mathrm{MYC}(\mathrm{t}=0.997, \mathrm{P}=0.501 ; \mathrm{t}=4.519, \mathrm{P}=0.139 ; \mathrm{t}=1.237$, $\mathrm{P}=0.433 ; \mathrm{t}=2.766, \mathrm{P}=0.221$ ) between these two groups.

The expression level of $\mathrm{P}-\mathrm{AKT}(\mathrm{t}=57.843, \mathrm{P}=0.011)$ was significantly lower in the HG-CCAT-1 $1^{-}$group than in the HG-EV group, but no significant differences in the expressions of PI3K ( $\mathrm{t}=0.596, \mathrm{P}=0.658), \mathrm{P}-\mathrm{PI} 3 \mathrm{~K}(\mathrm{t}=7.741$, $\mathrm{P}=0.082)$, AKT $(\mathrm{t}=0.850, \mathrm{P}=0.552), \mathrm{C}-\mathrm{MYC}(\mathrm{t}=0.528$, $\mathrm{P}=0.691)$, and $\mathrm{P}-\mathrm{C}-\mathrm{MYC}(\mathrm{t}=2.066, \mathrm{P}=0.287)$ were observed. There was no significant difference in the expressions of PI3K, P-PI3K, AKT, P-AKT, C-MYC, and P-C-MYC $(\mathrm{t}=4.930, \mathrm{P}=0.127 ; \mathrm{t}=11.643, \mathrm{P}=0.055 ; \mathrm{t}=5.659, \mathrm{P}=0.111$; $\mathrm{t}=6.656, \mathrm{P}=0.095)$ between LG-CCAT $-1^{-}$and HG-CCAT-1 groups.

\section{Discussion}

Hyperglycemia is an independent risk factor for colon cancer. Many epidemiological studies have shown that type 2 diabetes mellitus can increase the incidence of colon cancer (1-14). Our earlier study found that $29.67 \%$ of colon cancer patients were associated with hyperglycemia, and $14.83 \%$ were associated with diabetes (9). In this study, of the 200 patients with colon cancer, $65.50 \%$ had normal blood glucose; $30.50 \%$ had hyperglycemia, of which $14.50 \%$ had diabetes; and $4.00 \%$ had hypoglycemia, which was consistent with our previous reports and other related epidemiological findings $(3,14)$.

We used sequencing technology to screen out the high expression molecular spectrum in patients with colon cancer with hyperglycemia. We found that the expression of CCAT-1 RNA was significantly increased in colon cancer with hyperglycemia. We performed verification by qPCR and found that the expression of CCAT-1 RNA in tumor tissues of colon cancer patients with normal blood glucose levels was significantly higher than that in the distal normal intestinal mucosa of these patients $(\mathrm{P}<0.05)$. The expression of CCAT-1 RNA in tumor tissues was significantly higher than that in the distal normal intestinal mucosa of colon cancer patients with hyperglycemia $(\mathrm{P}<0.05)$. The expression of CCAT-1 RNA was significantly higher in the tumor tissue of colon cancer patients with hyperglycemia than in the tumor tissue of colon cancer patients with normal blood glucose $(\mathrm{P}<0.05)$. Furthermore, the expression of CCAT-1 RNA in distal normal intestinal mucosa showed no significant difference between colon cancer patients with 

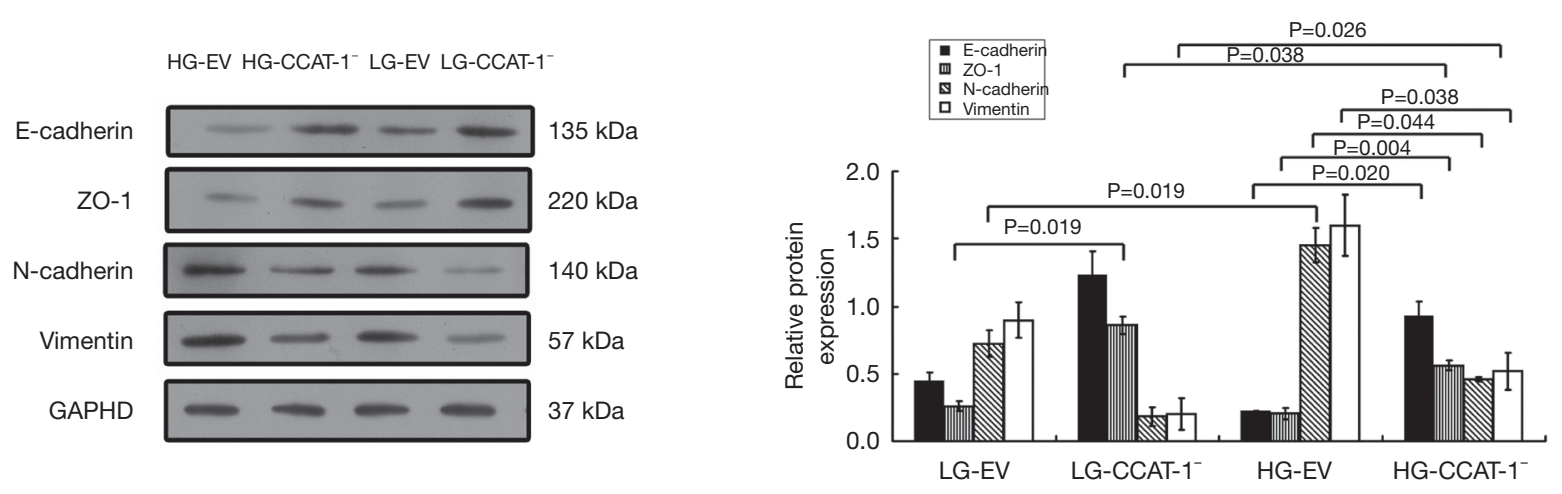

Figure 10 The effect of colon cancer-associated transcript-1 (CCAT-1) on epithelial-mesenchymal transition (EMT) markers' protein expressions in colon cancer cells cultured under different glucose concentrations. The protein expression of ZO-1 was significantly higher ( $\mathrm{t}=33.050, \mathrm{P}=0.019)$ in the $\mathrm{LG}-C C A T-1^{-}$group than in the LG-EV group. The protein expressions of E-cadherin and ZO-1 were significantly higher $(\mathrm{t}=31.079, \mathrm{P}=0.020 ; \mathrm{t}=143.200, \mathrm{P}=0.004)$ and those of $\mathrm{N}$-cadherin and vimentin were significantly lower ( $\mathrm{t}=14.491$, $\mathrm{P}=0.044 ; \mathrm{t}=16.853, \mathrm{P}=0.038)$ in the $\mathrm{HG}-C C A T-1^{-}$group than in the HG-EV group. The protein expression of ZO-1 was significantly lower ( $\mathrm{t}=16.768, \mathrm{P}=0.038)$, and vimentin was significantly higher $(\mathrm{t}=24.846, \mathrm{P}=0.026)$ in the HG-CCAT-1 ${ }^{-}$group than in the $\mathrm{LG}-C C A T-1^{-}$group. The protein expression of $\mathrm{N}$-cadherin was significantly higher $(\mathrm{t}=34.353, \mathrm{P}=0.019)$ in the HG-EV group than in the LG-EV group. HG$\mathrm{EV}$, empty vector transfected colon cancer cells cultured with high glucose; HG-CCAT- $1^{-}$, CCAT- $1^{-}$silenced colon cancer cells cultured with low glucose; LG-EV, empty vector transfected colon cancer cells cultured with low glucose; LG-CCAT1 ${ }^{-}$, CCAT- $1^{-}$silenced colon cancer cells cultured with low glucose.
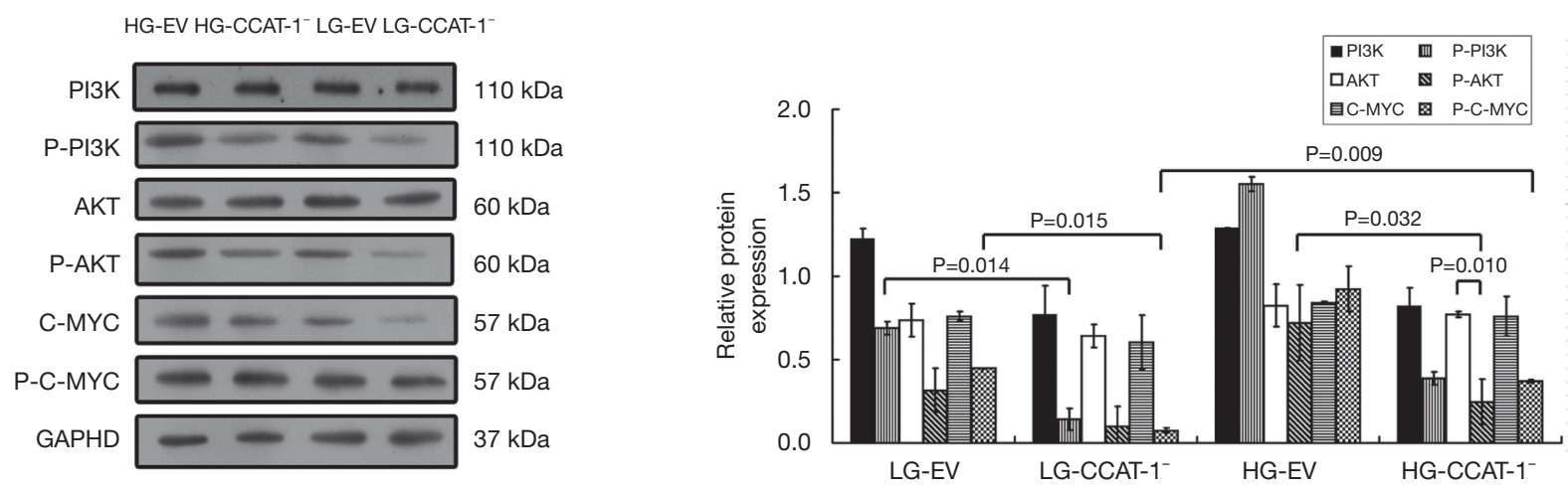

Figure 11 The effect of colon cancer-associated transcript-1 (CCAT-1) on the PI3K/Akt/C-MYC pathway expression in colon cancer cells under different glucose concentrations. P-Akt expression level decreased significantly $(\mathrm{t}=61.036, \mathrm{P}=0.010)$ compared with its unphosphorylated protein expression in the HG-CCAT-1 ${ }^{-}$group. P-PI3K and P-C-MYC expression levels were significantly lower in the LG-CCAT-1 ${ }^{-}$group than in the LG-EV group ( $\left.\mathrm{t}=46.442, \mathrm{P}=0.014 ; \mathrm{t}=42.208, \mathrm{P}=0.015\right)$. Furthermore, the expression levels of $\mathrm{P}-\mathrm{AKT}$ $(\mathrm{t}=20.136, \mathrm{P}=0.032)$ were significantly lower in the HG-CCAT-1- ${ }^{-}$group than in the HG-EV group. P-C-MYC expression levels were significantly higher in the HG-CCAT-1 ${ }^{-}$group than in the LG-CCAT-1 ${ }^{-}$group $(\mathrm{t}=68.504, \mathrm{P}=0.009)$. HG-EV, empty vector transfected colon cancer cells cultured with high glucose; HG-CCAT-1 ${ }^{-}$, CCAT-1 ${ }^{-}$silenced colon cancer cells cultured with low glucose; LG-EV, empty vector transfected colon cancer cells cultured with low glucose; LG-CCAT-1 ${ }^{-}$, CCAT-1-silenced colon cancer cells cultured with low glucose.

hyperglycemia and normal blood glucose $(\mathrm{P}>0.05)$. Thus, we hypothesized that $C C A T-1$ plays dual regulatory roles, namely in the development of colon cancer and glucose metabolism in the tumor tissue.
We used qPCR to verify the expression of CCAT-1 RNA in different colon cancer cells (LoVo and SW620) and normal colon cells (FHC). We found that the expression of CCAT-1 RNA in LoVo and SW620 cells was significantly 
higher than that in FHC cells. CCAT-1 RNA expression was the most significant in the SW620 cell line; as a standby cell line, we designed the shRNA of CCAT-1 and a transfected SW620 cell line with it.

To investigate the effect of CCAT-1 on colon cancer cells' proliferation in different glucose levels, we used high and low glucose concentrations to culture SW620 cells transfected with silenced CCAT-1 or empty vectors. We used EDU flow cytometry to analyze the proliferation activity in four colon cancer cells: HG-CCAT-1- $\mathrm{HG}-\mathrm{EV}$,

Table 4 The effect of CCAT-1 on the volume of colon cancer xenografts in nude mice with different blood glucose

\begin{tabular}{lc}
\hline Group & $\begin{array}{c}\text { Colon cancer cells transplanted } \\
\text { from tumor volume in nude mice }\left(\mathrm{mm}^{3}\right)\end{array}$ \\
\hline NG-EV & $380.33 \pm 82.80$ \\
NG-CCAT-1 $^{-}$ & $134.00 \pm 58.41$ \\
HG-EV & $923.167 \pm 14.46$ \\
HG-CCAT-1 & $372.667 \pm 127.69$ \\
\hline
\end{tabular}

HG-EV, nude mice with hyperglycemia transplanted with empty vector-transfected colon cancer cells; HG-CCAT-1 ${ }^{-}$, nude mice with hyperglycemia transplanted with CCAT-1-silenced colon cancer cells; NG-EV, nude mice with normal blood glucose transplanted with empty vector-transfected colon cancer cells; NG-CCAT $-1^{-}$, nude mice with normal blood glucose transplanted with CCAT-1-silenced colon cancer cells.
LG-CCAT-1 ${ }^{-}$, and LG-EV. The results showed that the proliferation ability of $C C A T-1$-silenced colon cancer cells was significantly lower than empty vector-transfected colon cancer cells $(\mathrm{P}<0.05)$; further, the proliferation ability in colon cancer cells cultured with high glucose was higher than colon cancer cells cultured with low glucose groups $(\mathrm{P}<0.05)$. To verify the effect of $C C A T-1$ on the transplanted tumor's proliferation in nude mice with different blood glucose levels, we subcutaneously transplanted CCAT-1silenced colon cancer cells into nude mice. Four weeks later, we found that the tumor volume in the nude mice transplanted with CCAT-1-silenced colon cancer cells was significantly lower than that in nude mice transplanted with empty vector-transfected colon cancer cells $(\mathrm{P}<0.05)$; the tumor volume in the nude mice with hyperglycemia was significantly larger than that in the nude mice with normal blood glucose levels $(\mathrm{P}<0.05)$. The results showed that CCAT-1 could promote the proliferation of colon cancer cells in vitro and in vivo, and high glucose levels could enhance the effect of $C C A T-1$ on tumor proliferation.

Lactic acid and glucose are essential energy sources in cancer $(19,20)$. Insulin resistance is also strongly associated with the progression of colon cancer (21). To investigate the effect of CCAT-1 on glucose metabolism in colon cancer cells, we performed ELISA and detected the glucose and lactic acid levels in the abovementioned four groups of colon cancer cells. The results showed that the glucose and
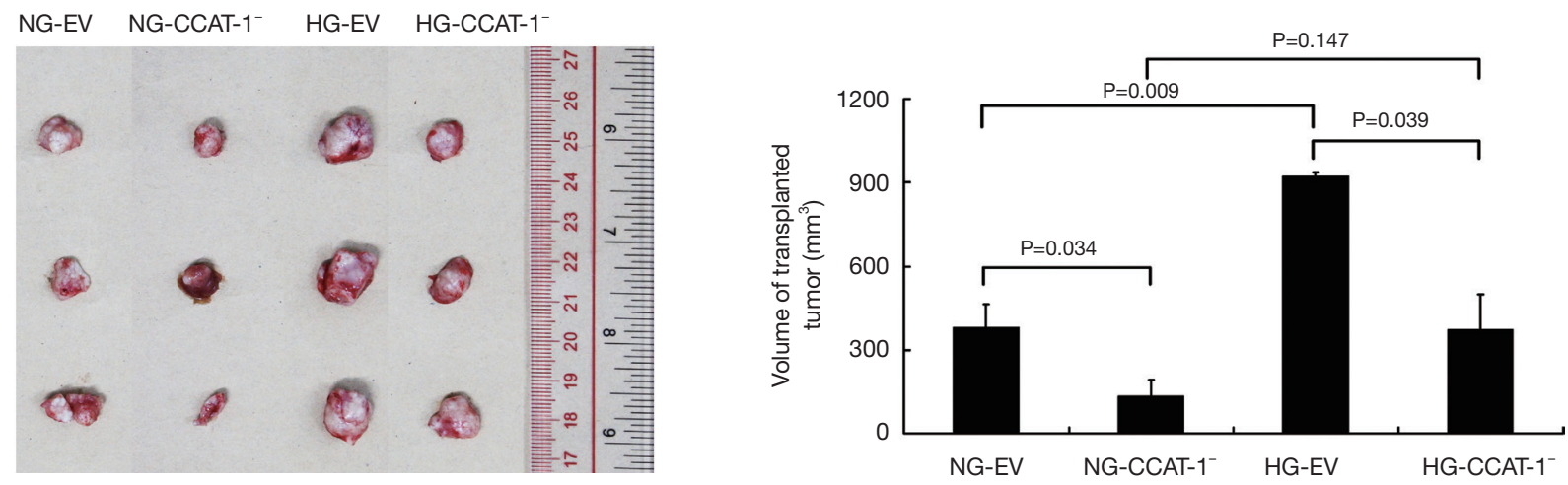

Figure 12 The effect of colon cancer-associated transcript-1 (CCAT-1) on the volume of colon cancer xenografts in nude mice with different blood glucose concentrations. The tumor volume of nude mice was significantly lower in the NG-CCAT-1 ${ }^{-}$group than in the NG-EV group ( $\mathrm{t}=5.257, \mathrm{P}=0.034)$; further, the tumor volume of nude mice was significantly lower in the HG-CCAT-1 ${ }^{-}$group than in the HG-EV group $(\mathrm{t}=4.892, \mathrm{P}=0.039)$. Finally, the tumor volume of nude mice in the HG-EV group was significantly higher than that in the NG-EV group ( $\mathrm{t}=10.231, \mathrm{P}=0.009)$. NG-EV, normal blood glucose nude mice transplanted with empty vector transfected colon cancer cells; NG-CCAT-1 ${ }^{-}$, normal blood glucose nude mice transplanted with CCAT-1 silenced colon cancer cells; HG-EV, hyperglycemia nude mice transplanted with empty vector transfected colon cancer cells; HG-CCAT-1 ${ }^{-}$, hyperglycemia nude mice transplanted with CCAT-1 silenced colon cancer cells. 

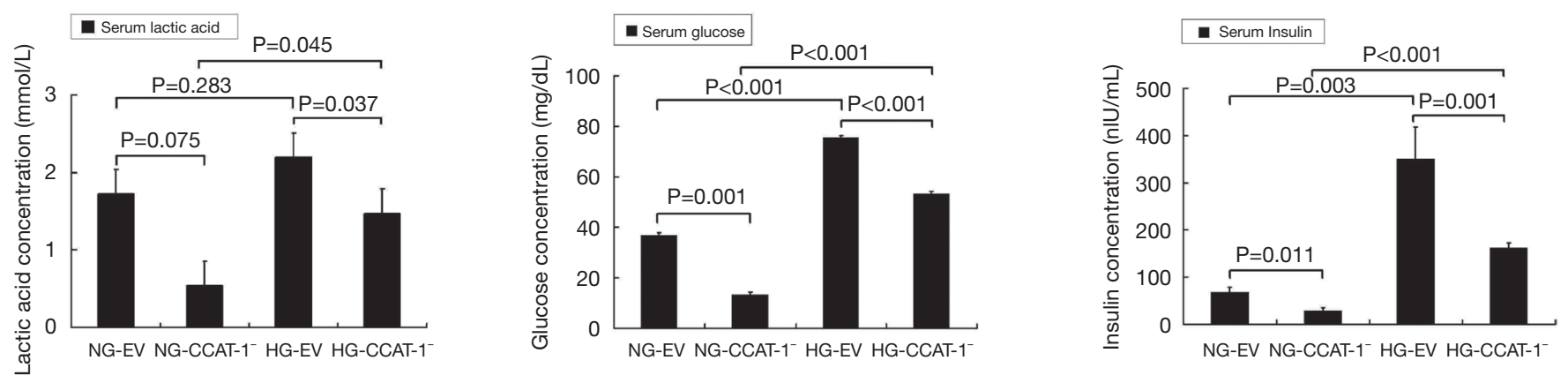

Figure 13 The effect of colon cancer-associated transcript-1 (CCAT-1) on serum glucose, lactic acid, and insulin levels in nude mice with different blood glucose concentrations. The levels of serum glucose $(\mathrm{t}=13.369, \mathrm{P}=0.001)$ and insulin $(\mathrm{t}=5.571, \mathrm{P}=0.011)$ were significantly lower in the NG-CCAT-1 $1^{-}$group than in the NG-EV group; the levels of serum glucose $(\mathrm{t}=17.689, \mathrm{P}<0.001)$, lactic acid ( $\left.\mathrm{t}=5.033, \mathrm{P}=0.037\right)$, and insulin $(\mathrm{t}=5.817, \mathrm{P}=0.010)$ were significantly lower in the HG-CCAT-1 ${ }^{-}$group than in the HG-EV group. Furthermore, the levels of serum glucose $(\mathrm{t}=28.352, \mathrm{P}<0.001)$, lactic acid $(\mathrm{t}=4.539, \mathrm{P}=0.045)$, and insulin $(\mathrm{t}=19.024, \mathrm{P}<0.001)$ were significantly higher in the HGCCAT- $1^{-}$group than in the NG-CCAT-1 ${ }^{-}$group. The levels of serum glucose $(\mathrm{t}=19.575, \mathrm{P}<0.001)$ and insulin $(\mathrm{t}=8.560, \mathrm{P}=0.003)$ were significantly higher in the HG-EV group than in the NG-EV group. HG-EV, nude mice with hyperglycemia transplanted with empty vector-transfected colon cancer cells; HG-CCAT-1 ${ }^{-}$, nude mice with hyperglycemia transplanted with CCAT-1-silenced colon cancer cells; NG-EV, nude mice with normal blood glucose transplanted with empty vector-transfected colon cancer cells; NG-CCAT-1 ${ }^{-}$, nude mice with normal blood glucose transplanted with CCAT-1-silenced colon cancer cells.
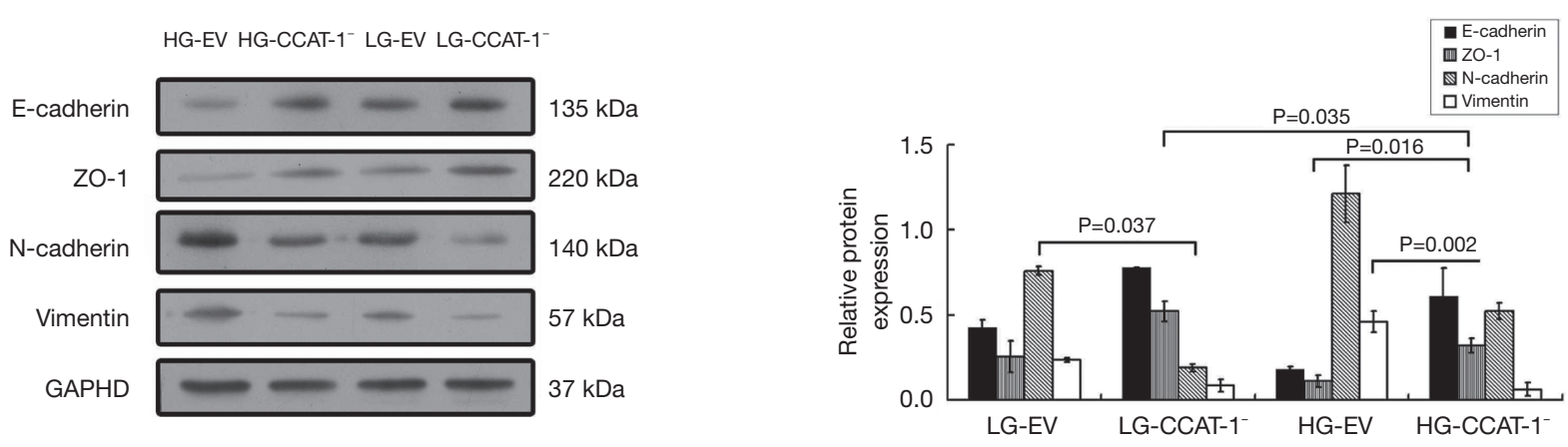

Figure 14 The effect of colon cancer-associated transcript-1 (CCAT-1) on the expression levels of epithelial-mesenchymal transition (EMT) marker proteins in nude mice with different blood glucose concentrations. N-cadherin expression levels were significantly lower in the LGCCAT-1 $1^{-}$group than in the $\mathrm{LG}-\mathrm{EV}$ group $(\mathrm{t}=17.114, \mathrm{P}=0.037)$. The expression levels of $\mathrm{ZO}-1$ were significantly higher $(\mathrm{t}=40.082$, $\mathrm{P}=0.016)$, and vimentin was significantly lower $(\mathrm{t}=28.320, \mathrm{P}=0.022)$ in the HG-CCAT-1 ${ }^{-}$group than in the HG-EV group. The expression levels of ZO-1 were significantly lower $(\mathrm{t}=18.002, \mathrm{P}=0.035)$ in the $\mathrm{HG}-C C A T-1^{-}$group than in the LG-CCAT-1 ${ }^{-}$group. HG-EV, empty vector transfected colon cancer cells cultured with high glucose; HG-CCAT-1 ${ }^{-}$, CCAT-1 silenced colon cancer cells cultured with low glucose; LG-EV, empty vector transfected colon cancer cells cultured with low glucose; LG-CCAT1 ${ }^{-}$, CCAT- $1^{-}$silenced colon cancer cells cultured with low glucose.

lactic acid levels in the CCAT-1-silenced colon cancer cells were significantly lower than those in the empty vectortransfected colon cancer cells $(\mathrm{P}<0.05)$. The results show that CCAT-1 upregulates glucose and lactic acid levels in colon cancer cells through mechanisms, providing energy supply to colon cancer cells. To investigate the effect of CCAT-1 on glucose metabolism in vivo, we performed ELISA following a biochemical approach and detected the 

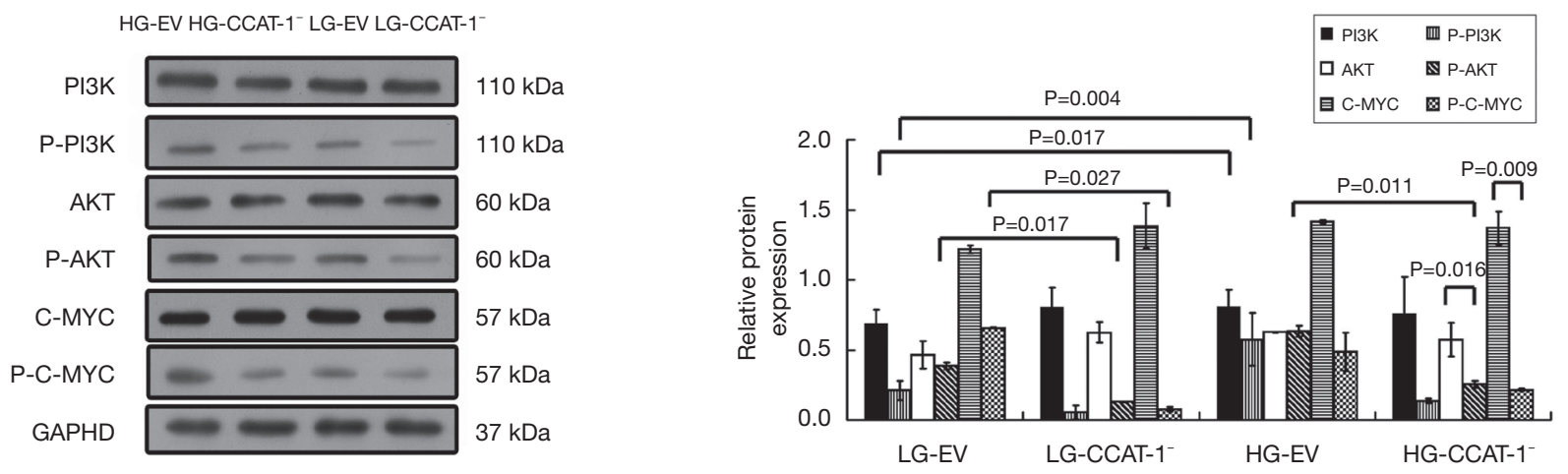

Figure 15 The effect of colon cancer-associated transcript-1 (CCAT-1) on the PI3K/Akt/C-MYC pathway in nude mice with different blood glucose concentrations. p-Akt and p-C-MYC levels were significantly lower than their unphosphorylated counterparts $(\mathrm{t}=40.486, \mathrm{P}=0.016$; $\mathrm{t}=67.239, \mathrm{P}=0.009)$ in the HG-CCAT-1 ${ }^{-}$group. Furthermore, P-AKT expression levels $(\mathrm{t}=37.844, \mathrm{P}=0.017)$ and $\mathrm{P}-\mathrm{C}-\mathrm{MYC}(\mathrm{t}=23.894$, $\mathrm{P}=0.027)$ were significantly lower in the $\mathrm{HG}-C C A T-1^{-}$group than in the $\mathrm{LG}-\mathrm{EV}$ group. The expression level of $\mathrm{P}-\mathrm{AKT}(\mathrm{t}=57.843, \mathrm{P}=0.011)$ was significantly lower in the HG-CCAT-1 $1^{-}$group than in the HG-EV group. HG-EV, nude mice with hyperglycemia transplanted with empty vector-transfected colon cancer cells; HG-CCAT- ${ }^{-}$, nude mice with hyperglycemia transplanted with CCAT-1-silenced colon cancer cells; NG-EV, nude mice with normal blood glucose transplanted with empty vector-transfected colon cancer cells; NG-CCAT-1 ${ }^{-}$, nude mice with normal blood glucose transplanted with CCAT-1-silenced colon cancer cells.

levels of glucose, lactic acid, and insulin in serum samples of nude mice with different blood glucose levels. The results showed that the blood glucose, lactic acid, and insulin levels in hyperglycemic nude mice transplanted with CCAT-1silenced colon cancer cells were significantly lower than those in hyperglycemic nude mice transplanted with empty vector-transfected colon cancer cells $(\mathrm{P}<0.05)$. The blood glucose, lactic acid, and insulin levels in hyperglycemic nude mice transplanted with CCAT-1-silenced colon cancer cells were significantly higher than those in normal blood glucose nude mice transplanted with CCAT-1-silenced colon cancer cells $(\mathrm{P}<0.05)$.

Further results revealed that CCAT-1 could upregulate the level of blood glucose, lactic acid, and insulin in vivo and improve glucose metabolism in nude mice bearing tumors. Hyperglycemia could promote glucose level metabolism changes in nude mice transplanted with CCAT-1-silenced colon cancer cells; however, the specific mechanism underlying this needs to be clarified. Our study also found that CCAT-1 had no significant effect on lactic acid levels in nude mice with normal blood glucose transplanted with colon cancer cells, and hyperglycemia could not affect the lactic acid levels of nude mice transplanted with empty vector-transfected colon cancer cells alone.

The energy source of malignant tumors is mainly the glycolysis pathway $(22,23)$, and it is also reported that the glycolysis pathway in tumor cells can be regulated by long-chain non-coding RNAs (24,25). LDH-A, PKM2, and HK2 are the three major rate-limiting enzymes of the glycolysis pathway and play essential roles in colon cancer progression (26). To investigate the effect of CCAT-1 on the expression of these glycolysis rate-limiting enzymes in colon cancer cells cultured with different glucose concentrations, we used Western blotting and qPCR and determined the protein mRNA expression levels of LDH-A, PKM2, and HK2 in the four groups of colon cancer cells. The results showed that the protein and mRNA expression levels of LDH-A, PKM2, and HK2 in CCAT-1-silenced colon cancer cells cultured with low and high glucose levels were significantly lower in empty vector-transfected colon cancer cells $(\mathrm{P}<0.05)$. Furthermore, the protein and mRNA expressions of LDH-A, PKM2, and HK2 in CCAT-1silenced colon cancer cells cultured with high glucose were significantly higher than those in CCAT-1-silenced colon cancer cells cultured with low glucose $(\mathrm{P}<0.05)$. The results further showed that $C C A T-1$ could significantly increase the expression levels of glycolysis rate-limiting enzymes in colon cancer cells cultured in different glucose concentrations and promote lactic acid production to provide an energy source for the growth of colon cancer cells by upregulating the glycolytic pathway.

The anti-apoptotic effect is of great significance in the development of malignant tumor cells (27). It has been reported that $C C A T-1$ promotes autophagy in 
hepatocellular carcinoma (16). To investigate the effect of $C C A T-1$ on the apoptosis of colon cancer cells cultured with different glucose concentrations, we performed Western blotting and detected the protein expression levels of apoptosis regulatory genes such as Bcl-2 and Bax in four groups. The results showed that the protein expressions of Bcl-2 and Bax in CCAT-1-silenced colon cancer cells were significantly lower than those in empty vector-transfected colon cancer cells $(\mathrm{P}<0.05)$; the protein expressions of $\mathrm{Bcl}-2$ and Bax in colon cancer cells cultured with high glucose were significantly higher than those in colon cancer cells cultured with low glucose $(\mathrm{P}<0.05)$. The results also showed that $C C A T-1$ had an anti-apoptotic effect on colon cancer cells, and high glucose could promote this anti-apoptotic effect.

The Transwell migration assay was performed for detecting the migration ability of the four groups of colon cancer cells to investigate the effect of CCAT-1 on the migration of colon cancer cells cultured with different glucose concentrations. The results showed that the migration ability of $C C A T$-1-silenced colon cancer cells was significantly lower than that of the empty vector-transfected colon cancer cells $(\mathrm{P}<0.05)$; further, the migration ability of colon cancer cells cultured with high glucose concentration was higher than colon cancer cells cultured with low glucose concentration $(\mathrm{P}<0.05)$.

EMT is essentially a biological process for epithelial tumor cells to achieve invasion and metastasis ability. During EMT, epithelial cells lose cell polarity and connection with the basement membrane; E-cadherin, ZO1 , and other epithelial markers are downregulated, whereas vimentin and $\mathrm{N}$-cadherin are upregulated, inducing conditions for invasion and metastasis of the tumor (28). It has also been reported that long-chain non-coding RNA takes part in EMT regulation in tumor cells (29-31). To investigate whether $C C A T-1$ can promote the migration of colon cancer cells in different glucose concentrations by regulating the EMT process, we performed Western blotting and detected the protein expression of EMT markers in the abovementioned four groups. The results showed that the expression of E-cadherin and ZO-1 increased, and that of $\mathrm{N}$-cadherin and vimentin decreased significantly $(\mathrm{P}<0.05)$ in CCAT-1-silenced colon cancer cells cultured with high glucose compared with empty vectortransfection colon cancer cells cultured with high glucose. Furthermore, the expression of ZO-1 was significantly lower, and that of vimentin was significantly higher $(\mathrm{P}<0.05)$ in $C C A T-1$-silenced colon cancer cells cultured with high glucose than in CCAT-1-silenced colon cancer cells cultured with low glucose concentrations. However, CCAT-1 had no significant effect on the expression of EMT markers in colon cancer cells cultured with low glucose concentrations $(\mathrm{P}>0.05)$, and high glucose concentrations could not affect the expression of EMT markers alone. In the animal model study, we found that the expression of ZO-1 was significantly higher and that of vimentin was significantly lower in the tumor tissues of hyperglycemic nude mice transplanted with CCAT-1-silenced colon cancer cells than in tumor tissues of hyperglycemic nude mice transplanted with empty vector-transfected colon cancer cells $(\mathrm{P}<0.05)$. No significant difference in the EMT marker expressions was observed in tumor tissues between mice with hyperglycemia and mice with normal blood glucose levels that were transplanted with empty vector-transfected colon cancer cells $(\mathrm{P}>0.05)$ or CCAT-1-silenced colon cancer cells $(\mathrm{P}>0.05)$. The results mentioned above showed that CCAT-1 could improve colon cancer cells' migration ability by regulating the EMT process in a high glucose environment in vitro and vivo. A high glucose culture environment or hyperglycemia could improve the ability of CCAT-1 to regulate EMT and promote the migration of colon cancer cells, whereas this role of CCAT-1 in a low or normal glucose environment was not prominent.

PI3K/Akt pathway takes part in cell proliferation, differentiation, apoptosis, glucose transport, and other cell function regulations closely associated with tumor development and glucose metabolism regulation (3234). The tumor-driving gene C-MYC is a downstream regulatory gene of the PI3K/Akt pathway, which plays a vital role in the occurrence and development of malignant tumors (35). Other studies have shown that non-coding RNAs can regulate C-MYC and regulate colon cancer cells' metabolism and activity (36). However, whether CCAT-1 can activate the PI3K/Akt pathway and activate C-MYC under hyperglycemia and take part in colon cancer development is worthy of further evaluation. In vitro, we performed Western blotting to detect the expressions of PI3K, Akt, C-MYC, and phosphorylated proteins in the four abovementioned cell groups. The results showed that the expression of p-Akt was significantly lower than its unphosphorylated antibody in CCAT-1silenced colon cancer cells cultured under high glucose concentration $(\mathrm{P}<0.05)$, whereas the other proteins were not phosphorylated $(\mathrm{P}>0.05)$. Furthermore, the expression levels of P-PI3K and p-C-MYC were significantly lower in CCAT-1-silenced colon cancer cells cultured with low 
glucose concentrations than in empty vector-transfected colon cancer cells cultured with low glucose concentrations $(\mathrm{P}<0.05)$, and no significant difference was observed in the expression levels of other antibodies in this pathway. The expression level of p-Akt was significantly lower in CCAT1 -silenced colon cancer cells cultured with high glucose concentrations than in empty vector-transfected colon cancer cells cultured with high glucose concentrations $(\mathrm{P}<0.05)$, and no significant difference was observed in the expression of other antibodies. Furthermore, the expression of p-C-MYC was significantly higher in CCAT-1 silenced colon cancer cells cultured with high glucose concentrations than in CCAT-1-silenced colon cancer cells cultured with low glucose concentrations $(\mathrm{P}<0.05)$, and no significant difference was observed in the expression of other antibodies $(\mathrm{P}>0.05)$. No significant difference in PI3 K/Akt/C-MYC pathway was observed between empty vector-transfected colon cancer cells cultured with low glucose concentrations and those cultured with high glucose concentrations $(\mathrm{P}>0.05)$. Our in vitro study showed that $C C A T-1$ could promote Akt protein activation in colon cancer cells cultured with high glucose concentrations and upregulate the expression of $\mathrm{p}-\mathrm{PI} 3 \mathrm{~K}$ and $\mathrm{p}-\mathrm{C}-\mathrm{MYC}$ in colon cancer cells cultured with low glucose concentrations. In the in vivo study of model animals, we used Western blotting to detect the activation of PI3K/Akt/C-MYC pathway in tumor tissues of hyperglycemic nude mice with normal blood glucose levels transplanted with CCAT-1silenced or empty vector-transfected colon cancer cells. The results showed that the expression of p-Akt and p-CMYC was significantly lower than non-phosphorylated proteins in tumor tissues of hyperglycemic nude mice transplanted with CCAT-1-silenced colon cancer cells $(\mathrm{P}<0.05)$. The expression of $\mathrm{p}-\mathrm{Akt}$ and $\mathrm{p}-\mathrm{C}-\mathrm{MYC}$ was significantly lower in the tumor tissues of nude mice with normal blood glucose transplanted with CCAT-1-silenced colon cancer cells than in those of nude mice with normal blood glucose transplanted with empty vector-transfected colon cancer cells $(\mathrm{P}<0.05)$. The expression of $\mathrm{p}$-Akt was significantly lower in the tumor tissues of hyperglycemic nude mice transplanted with CCAT-1-silenced colon cancer cells than in those of hyperglycemic nude mice transplanted with empty vector-transfected colon cancer cells $(\mathrm{P}<0.05)$. There was no significant difference in the expression of any antibody in the tumor tissues of hyperglycemic nude mice transplanted with CCAT-1-silenced colon cancer cells and mouse tumor tissues with normal blood glucose transplanted with CCAT-1-silenced colon cancer cells
$(\mathrm{P}>0.05)$. The expression levels of PI3K and P-PI3K were significantly higher in hyperglycemic nude mice transplanted with empty vector-transfected colon cancer cells than in mice with normal blood glucose transplanted with empty vector-transfected colon cancer cells $(\mathrm{P}<0.05)$. Our in vivo study showed that CCAT-1 could promote Akt and C-MYC proteins' activation in hyperglycemic nude mouse tumor tissues. Further, the activation upregulated $\mathrm{p}-\mathrm{Akt}$ and $\mathrm{p}-\mathrm{C}-\mathrm{MYC}$ expression in mouse tumor tissues with normal blood glucose. Moreover, hyperglycemia can upregulate the expression of PI3K and P-PI3K in the tumor tissues of nude mice transplanted with empty vectortransfected colon cancer cells.

In conclusion, we report that $C C A T-1$ can enhance the proliferative activity of colon cancer cells by increasing the expression of glycolysis rate-limiting enzymes, improving the glucose metabolism levels, activating the Akt/C-MYC pathway, inhibiting apoptosis of colon cancer cells, and enhancing the migration activity of colon cancer cells by promoting the EMT process. A high-glucose environment in vivo and in vitro can further enhance the tumorpromoting effect of $C C A T-1$. Thus, CCAT-1 plays a dual regulatory role in developing colon cancer and glucose metabolism in tumor tissues and can be an essential intervention target for hyperglycemic patients with colon cancer.

\section{Acknowledgments}

Funding: The Research Project of Science and Technology of Zhejiang Province (2017C37177); The Medical Scientific Research Project of Health Commission of Zhejiang Province (2018KY775); The Research Project of Science and Technology of Huzhou City (2020GYB13); The Key Research Project of Science and Technology of Huzhou City (2018GZ34); The Development and Application of South Taihu Science and Technology Innovation Leading Talents Project; The Key Research Project of Graduate Education Association of Zhejiang Province (2019-008).

\section{Footnote}

Reporting Checklist: The authors have completed the ARRIVE reporting checklist. Available at http://dx.doi. org/10.21037/jgo-20-474

Data Sharing Statement: Available at http://dx.doi. org/10.21037/jgo-20-474 
Conflicts of Interest: All authors have completed the ICMJE uniform disclosure form (available at http://dx.doi. org/10.21037/jgo-20-474). The authors have no conflicts of interest to declare.

Etbical Statement: The authors are accountable for all aspects of the work in ensuring that questions related to the accuracy or integrity of any part of the work are appropriately investigated and resolved. All procedures performed in this study involving human participants were in accordance with the Declaration of Helsinki (as revised in 2013). The study was approved by Ethics Committee board of The First Affiliated Hospital of Huzhou University (No. 20170118003) and informed consent was taken from all the patients. Animal experiments have approved by the review of Ethics Committee board of The First Affiliated Hospital of Huzhou University (No.: 20170118003), and were performed in compliance with Chinese national or institutional guidelines for the care and use of animals.

Open Access Statement: This is an Open Access article distributed in accordance with the Creative Commons Attribution-NonCommercial-NoDerivs 4.0 International License (CC BY-NC-ND 4.0), which permits the noncommercial replication and distribution of the article with the strict proviso that no changes or edits are made and the original work is properly cited (including links to both the formal publication through the relevant DOI and the license). See: https://creativecommons.org/licenses/by-nc-nd/4.0/.

\section{References}

1. Miłek T, Forysiński K, Myrcha P, et al. Diabetes association of polyps and colon cancer. Pol Przegl Chir 2019;91:9-12.

2. Chang CK and Ulrich CM. Hyperinsulinaemia and hyperglycaemia: possible risk factors of colorectal cancer among diabetic patients. Diabetologia 2003;46:595-607.

3. de Kort S, Simons CCJM, van den Brandt PA, et al. Diabetes mellitus, genetic variants in the insulin-like growth factor pathway and colorectal cancer risk. Int J Cancer 2019;145:1774-81.

4. Overbeek JA, Kuiper JG, van der Heijden AAWA, et al. Sex- and site-specific differences in colorectal cancer risk among people with type 2 diabetes. Int J Colorectal Dis 2019;34:269-76.

5. Ma Y, Yang W, Song M, et al. Type 2 diabetes and risk of colorectal cancer in two large U.S. prospective cohorts. $\mathrm{Br}$
J Cancer 2018;119:1436-42.

6. Chubak J, Yu O, Ziebell RA, et al. Risk of colon cancer recurrence in relation to diabetes. Cancer Causes Control 2018;29:1093-103.

7. Hu D, Mao Y, Xu G, et al. Gut flora shift caused by timerestricted feeding might protect the host from metabolic syndrome, inflammatory bowel disease and colorectal cancer. Transl Cancer Res 2018;7:1282-9.

8. Wu J, Chen J, Xi Y, et al. High glucose induces epithelialmesenchymal transition and results in the migration and invasion of colorectal cancer cells. Exp Ther Med 2018;16:222-30.

9. Cui G, Zhang T, Ren F, et al. High blood glucose levels correlates with tumor malignancy in colorectal cancer patients. Med Sci Monit 2015;21:3825-33.

10. González N, Prieto I, Del Puerto-Nevado L, et al. 2017 update on the relationship between diabetes and colorectal cancer: epidemiology, potential molecular mechanisms and therapeutic implications. Oncotarget 2017;8:18456-85.

11. Herrigel DJ, Moss RA. Diabetes mellitus as a novel risk factor for gastrointestinal malignancies. Postgrad Med 2014;126:106-18.

12. Zanders MM, Vissers PA, Haak HR, et al. Colorectal cancer, diabetes and survival: epidemiological insights. Diabetes Metab 2014;40:120-7.

13. Ulaganathan V, Kandiah M, Mohd Shariff Z. A casecontrol study of the association between metabolic syndrome and colorectal cancer: a comparison of International Diabetes Federation, National Cholesterol Education Program Adults Treatment Panel III, and World Health Organization definitions. J Gastrointest Oncol. 2018;9:650-63.

14. Chiao EY, Nambi PV, Naik AD. The impact of diabetes process and outcome quality measures on overall survival in patients with co-morbid colorectal cancer. J Cancer Surviv 2010;4:381-7.

15. Nissan A, Stojadinovic A, Mitrani-Rosenbaum S, et al. Colon cancer associated transcript-1: a novel RNA expressed in malignant and pre-malignant human tissues. Int J Cancer 2012;130:1598-606.

16. Guo J, Ma Y, Peng X, et al. LncRNA CCAT1 promotes autophagy via regulating ATG7 by sponging miR181 in hepatocellular carcinoma. J Cell Biochem 2019;120:17975-83.

17. American Diabetes Association. Diagnosis and classification of diabetes mellitus. Diabetes Care 2004;27 Suppl 1:S5-S10.

18. Xin Y, Jiang X, Wang Y, et al. Insulin-Producing Cells 
Differentiated from Human Bone Marrow Mesenchymal Stem Cells In Vitro Ameliorate Streptozotocin-Induced Diabetic Hyperglycemia. PLoS One 2016;11:e0145838.

19. Goodwin ML, Gladden LB, Nijsten MW, et al. Lactate and Cancer: Revisiting the Warburg Effect in an Era of Lactate Shuttling. Front Nutr 2015;1:27.

20. Liao YF, Yin S, Chen ZQ, et al. High glucose promotes tumor cell proliferation and migration in lung adenocarcinoma via the RAGE-NOXs pathway. Mol Med Rep 2018;17:8536-41.

21. Komninou D, Ayonote A, Richie JP Jr, et al. Insulin resistance and its contribution to colon carcinogenesis. Exp Biol Med (Maywood) 2003;228:396-405.

22. Shi Y, Liu S, Ahmad S, Gao Q. Targeting Key Transporters in Tumor Glycolysis as a Novel Anticancer Strategy. Curr Top Med Chem 2018;18:454-66.

23. Marín-Hernández A, Rodríguez-Enríquez S, VitalGonzález PA, et al. Determining and understanding the control of glycolysis in fast-growth tumor cells. FEBS J 2006;273:1975-88.

24. He Z, You C, Zhao D. Long non-coding RNA UCA1/ miR-182/PFKFB2 axis modulates glioblastoma-associated stromal cells-mediated glycolysis and invasion of glioma cells. Biochem Biophys Res Commun 2018; 500:569-76.

25. Song $\mathrm{J}, \mathrm{Wu} \mathrm{X}$, Liu F, et al. Long non-coding RNA PVT1 promotes glycolysis and tumor progression by regulating miR-497/HK2 axis in osteosarcoma. Biochem Biophys Res Commun 2017;490:S0006291X17311439.

26. Wang H, Peng R, Chen X, et al. Effect of HK2, PKM2 and LDHA on Cetuximab efficacy in metastatic colorectal cancer. Oncol Lett 2018;15:5553.

27. Fulda S. Tumor resistance to apoptosis. Int J Cancer 2009;124:511-5.

Cite this article as: Cui G, Huang Y, Feng W, Yao Y, Zhou H, Li X, Gong H, Liu J, Luo Y, Sun Y, Zhang M, Luo Y, Zhang T. Colon cancer-associated transcript-1 enhances glucose metabolism and colon cancer cell activity in a high-glucose environment in vitro and in vivo. J Gastrointest Oncol 2020;11(6):1164-1185. doi: 10.21037/jgo-20-474
28. Cao H, Xu E, Liu H, et al. Epithelial-mesenchymal transition in colorectal cancer metastasis: A system review. Pathol Res Pract 2015;211:557-69.

29. Xiong HG, Li H, Xiao Y, et al. Long noncoding RNA MYOSLID promotes invasion and metastasis by modulating the partial epithelial-mesenchymal transition program in head and neck squamous cell carcinoma. J Exp Clin Cancer Res 2019;38:278.

30. Han R, Chen S, Wang J, et al. LncRNA UCA1 affects epithelial-mesenchymal transition, invasion, migration and apoptosis of nasopharyngeal carcinoma cells. Cell Cycle 2019;18:3044-53.

31. Heery R, Finn SP, Cuffe S, et al. Long Non-Coding RNAs: Key Regulators of Epithelial-Mesenchymal Transition, Tumour Drug Resistance and Cancer Stem Cells. Cancers (Basel) 2017;9:38.

32. Yap TA, Bjerke L, Clarke PA, et al. Drugging PI3K in cancer: refining targets and therapeutic strategies. Curr Opin Pharmacol 2015;23:98-107.

33. Papadatos-Pastos D, Rabbie R, Ross P, et al. The role of the PI3K pathway in colorectal cancer. Crit Rev Oncol Hematol 2015;94:18-30.

34. Schultze SM, Hemmings BA, Niessen M, Tschopp O. PI3K/AKT, MAPK and AMPK signalling: protein kinases in glucose homeostasis. Expert Rev Mol Med 2012;14:e1.

35. Allen-Petersen BL, Sears RC. Mission Possible: Advances in MYC Therapeutic Targeting in Cancer. BioDrugs 2019;33:539-53.

36. Feng J, Ma J, Liu S, et al. A noncoding RNA LINC00504 interacts with c-Myc to regulate tumor metabolism in colon cancer. J Cell Biochem 2019;120:14725-34.

(English Language Editor: J. Chapnick) 